\title{
Xue-fu-Zhu-Yu decoction protects rats against retinal ischemia by downregulation of HIF-1a and VEGF via inhibition of RBP2 and PKM2
}

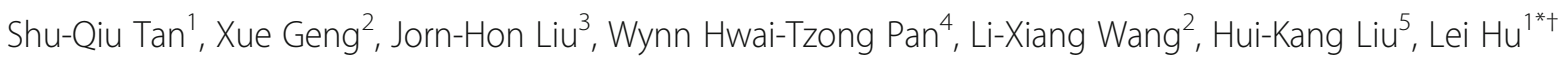
and Hsiao-Ming Chao $3,4,6^{*+}$

\begin{abstract}
Background: Retinal ischemia-related eye diseases result in visual dysfunction. This study investigates the protective effects and mechanisms of Xue-Fu-Zhu-Yu decoction (XFZYD) with respect to retinal ischemia.

Methods: Retinal ischemia (I) was induced in Wistar rats by a high intraocular pressure (HIOP) of $120 \mathrm{mmHg}$ for $1 \mathrm{~h}$, which was followed by reperfusion of the ischemic eye; the fellow untreated eye acted as a control. Electroretinogram $(E R G)$, biochemistry and histopathology investigations were performed.

Results: Significant ischemic changes occurred after ischemia including decreased ERG b-wave ratios, less numerous retinal ganglion cells (RGCS), reduced inner retinal thickness, fewer choline acetyltransferase (ChAT) labeled amacrine cell bodies, increased glial fibrillary acidic protein (GFAP) immunoreactivity and increased vimentin Müller immunolabeling. These were accompanied by significant increases in the mRNA/protein concentrations of vascular endothelium growth factor, hypoxia-inducible factor-1a, pyruvate kinase $\mathrm{M} 2$ and retinoblastoma-binding protein 2. The ischemic changes were concentration-dependently and significantly altered when XFZYD was given for seven consecutive days before or after retina ischemia, compared to vehicle. These alterations included enhanced ERG b-wave amplitudes, more numerous RGCs, enhanced inner retinal thickness, a greater number of ChAT immunolabeled amacrine cell bodies and decreased GFAP/vimentin immunoreactivity. Furthermore, decreased mRNA levels of VEGF, HIF-1a, PKM2, and RBP2 were also found. Reduced protein concentrations of VEGF, HIF-1a, PKM2, and RBP2 were also demonstrated. Furthermore, there was an inhibition of the ischemia-associated increased ratios (target protein/ $\beta$-actin) in the protein levels of VEGF, HIF-1a, PKM2, and RBP2, which were induced by Shikonin, JIB-04 or Avastin.
\end{abstract}

Conclusion: XFZYD would seem to protect against well-known retinal ischemic changes via a synergistic inhibition of RBP2 and PKM2, as well as down-regulation of HIF-1a and a reduction in VEGF secretion.

\footnotetext{
*Correspondence: misshulei@126.com; hsiaoming.chao@gmail.com

${ }^{\dagger}$ Equal contributors

'Department of Ophthalmology, Affiliated Hospital of Taishan Medical

University, Taishan, Shandong, China

${ }^{3}$ Department of Ophthalmology, Cheng Hsin General Hospital, Taipei, Taiwan

Full list of author information is available at the end of the article
} 


\section{Background}

Retinal ischemia related diseases include central retinal artery occlusion (CRAO), central retinal vein occlusion (CRVO), branch retinal artery occlusion (BRAO), branch retinal vein occlusion (BRVO), glaucoma, and age-related macular degeneration (AMD) [1-3]. All of these disorders can result in serious complications and thus the treatment of retinal ischemia is vital to patient outcomes.

Glutamate receptor rich retinal ganglion cells (RGCs) and amacrine cells, and their neuronal fibers are situated in the inner retina, which makes them susceptible to ischemia/reperfusion (I/R) injury $[1,3]$. After $I / R$, enhanced vimentin immunoreactivity in Müller cells can be seen [4]. Retinal or choroidal ischemia associated angiogenesis [5] often results in subretinal fluid and bleeding, which in turn leads to visual dysfunction. It is thus important to discover novel approaches that are able to stimulate self-protective mechanisms within the eye and that help to avoid detrimental neovascularization. Elevated concentrations of the hypoxia-inducible factor-1 $\alpha$ (HIF-1 $\alpha)$ have been demonstrated after retinal ischemia [6]. HIF-1 $\alpha$ interacts with hypoxia dependence components of various hypoxia related genes and upregulates the level of vascular endothelium growth factor (VEGF) [6]. Liu et al. [7] have also shown that oxidative stress in the human retinal pigment epithelium leads to VEGF up-regulation. All the above results support the hypothesis that up-regulation of HIF- $1 \alpha$ and VEGF in the retina is directly related to ischemic insult. The KDM5/ JARID1 family of Fe(II)- and $\alpha$-ketoglutarate-dependent demethylases remove methyl groups from tri- and dimethylated lysine 4 of histone H3. Figure 2c of Wang et al. [8] demonstrated that purified Jumonji demethylases representing several subfamilies exhibited distinct sensitivities to JIB-04 in vitro, with JARID1A (KDM5A, also known as retinoblastoma-binding protein 2, RBP2) being the most sensitive $(\mathrm{IC50}=230 \mathrm{nM})$. Other proteins include JMJD3 (KDM6B) and JMJD2C (KDM4C), which were more resistant (IC50 $\sim 1 \mu \mathrm{M}$ ) to JIB-04. Presently, JIB-04, a paninhibitor of the Jumonji demethylase superfamily, was thus selected to observe the inhibition of RBP2 upregulation in retinal ischemia. Pyruvate kinase (PK), glycolytic enzyme, catalytically convert phosphoenolpyruvate into pyruvate, generating one molecule of ATP. In addition, the PKM2 inhibitor shikonin [9], and the anti-VEGF agent avastin was presently selected to observe the inhibition of PKM2 and/or VEGF overexpression after retinal ischemic insult. An investigation as to whether an overexpression of VEGF, HIF-1 $\alpha$, PKM2 and RBP2 coexists in the ischemic retina has also been included in the present investigation.

Xue-Fu-Zhu-Yu decoction (XFZYD) is a famous traditional Chinese medicine formula that has been used to manage with cardiovascular disorders for several centuries [10]. The study of Lee et al. [11] suggested that XFZYD increased the potential of recombinant tissue plasminogen activator (tPA) as a neuroprotection agent against rat brain ischemia. The report of Zhou et al. [12] has also indicated that XFZYD seems to be able to alleviate hypoxia and protect liver sinusoidal endothelial cell function and does this by decreasing the levels of VEGF and HIF-1 $\alpha$. The formulation of XFZYD consists of eleven components (with respective representative active compounds in the bracket), namely Radix Angelicae Sinensis (Dang Gui: ferulic acid) [13, 14], Radix Rehmanniae glutinosae (Di Huang: catalpol) [15], Radix Paeoniae Rubra (Chi Shao: peoniflorin) [16], Rhizoma Ligustici Chuanxiong (Chuan Xiong: ferulic acid) [13, 14], Semen Pruni Persicae (Táo Rén: amygdalin) [17], Flos Carthami Tinctorii (Hong Hua: hydroxysafflor yellow A, HSYA) [18], Radix Glycyrrhizae Uralensis (Gan Cao: glycyrrhizin) [19], Fructus Auranti (Zhi Qiao: costunolide) [20], Radix Bupleuri Chinense (Chai Hu: saikosaponin) [21], Radix Achyranthis Bidentatae (Niu Xi: Achyranthes bidentata polysaccharides) [22], and Radix Platycodi Grandiflori (Jie Geng: platycodins) [23]. The important known effects of the defined active compounds described above are as follows. Ferulic acid has been proved to scavenge hydroxyl radical and is able to provide neuroprotection against retinal ischemia [13, 14]. Catalpol and the Achyranthes bidentata polysaccharides have antioxidative potential [15, 22]. Peoniflorin [16], amygdalin [17], HSYA [18], glycyrrhizin [19], costunolide [20] and saikosaponin [21] are able to protect against brain ischemia. Furthermore, amygdalin and HSYA have been shown to act additively by decreasing plasma viscosity and platelet aggregation. Aqueous extract from Platycodon grandiflorum such as platycodins [23] has a significant hepatoprotective effect and acts by reducing nitric oxide and counteracting lipid peroxidation dose-dependently.

The purpose of the current research is to investigate if XFZYD is able to alleviate retinal ischemic insult and to explore the decoction's influences on electroretinogram (ERG), the density of RGCs, retinal thickness, choline acetyltransferase (ChAT) immunopositive amacrine cells, and glial fibrillary acidic protein (GFAP) immunolabelling of Müller cells and vimentin immunolabelling of Müller cells. In addition, the mRNA and protein concentrations of VEGF, HIF-1 $\alpha$, PKM2 and RBP2 were analyzed by real-time polymerase chain reaction ( $\mathrm{rPCR}$ ) and Western blot, respectively, in the presence/absence of XFZYD.

\section{Methods}

\section{Animals}

Animals were utilized based on the Association for Research in Vision and Ophthalmology Statement for the Use of Animals in Ophthalmology and Vision 
Research, and all the experiments were agreed to the Institutional Animal Care and Use Committee at Cheng Hsin General Hospital (CHGH; Taipei, Taiwan; Approval No: CHIACUC 104-05). Six-week-old male Wistar rats (BioLasco, Taipei, Taiwan) were bred in a large plastic cage (Shineteh Instruments Co., Ltd., Taipei, Taiwan) containing fewer than six rats at a humidity of $40-60 \%$ and at $19-23{ }^{\circ} \mathrm{C}$. The rats $(n=115)$ were arbitrarily allocated into one of the following groups: Normal $(n=12)$, Sham ( $n=16-1=15$; one rat died during flurogold retrograde labeling), Vehicle $+\mathrm{I} / \mathrm{R}(n=16), \mathrm{XFZYD}_{1.35}+\mathrm{I} / \mathrm{R}$ $(n=16), \mathrm{XFZYD}_{2.7}+\mathrm{I} / \mathrm{R}(n=16), \mathrm{I} / \mathrm{R}+$ Vehicle $(n=5), \mathrm{I} / \mathrm{R}+\mathrm{XFZYD}_{1.35}(n=6), \mathrm{I} / \mathrm{R}+\mathrm{XFZYD}_{2.7}$ $(n=16)$, and $\mathrm{I} / \mathrm{R}+$ Inhibitor (Shikonin, $n=4$; JIB-04, $n=4-1=3$ : one JIB-04 blot was ill-defined; Avastin, $n=4)$. The number of the rats used in this study totaled 120, including 5 animals that died during the induction of pressure-induced retinal ischemia (Additional file 1). All rats were kept on a 12-h light/dark cycle with 12-15 air changes per hour. The rats received food and water ad libitum. The rat experiments were carried out in a manner that followed the Animal Research: Reporting of In Vivo Experiments (ARRIVE) guidelines.

\section{Animal anesthesia and euthanasia}

Anesthesia was carried out using $100 \mathrm{mg} / \mathrm{kg}$ ketamine (Pfizer, NY, USA) and $5 \mathrm{mg} / \mathrm{kg}$ xylazine (Sigma-Aldrich, MO, USA), which were injected intraperitoneally into the rats. An intraperitoneal (i.p.) injection of at least $140 \mathrm{mg} / \mathrm{kg}$ sodium pentobarbital (SCI Pharmtech, Taoyuan, Taiwan) was given to sacrifice the rats in a considerate and painless manner (Scientific Procedures Act 1986).

\section{Retinal ischemia induction}

The rats (200-250 g) were constrained in a stereotaxic frame under i.p. anesthesia induced by the defined doses of ketamine and xylazine. A high intraocular pressure (HIOP) of up to $120 \mathrm{mmHg}$ for $60 \mathrm{~min}$ was induced by cannulating the anterior chamber of the ischemic eye with a 30-gauge needle attached to a raised normal saline bottle. The detection of a pale retina indicated the establishment of retinal ischemia [1, 2, 24]. As a sham control, one eye of a control rat was given the same procedure without elevating the saline bottle [2].

\section{Drug provision}

An intake of 1.35 or $2.7 \mathrm{~g} / \mathrm{kg} /$ day XFZYD (Sun Ten Pharmaceutical CO, Taichung, Taiwan) was administered for seven continuous days before or after HIOP induced retinal ischemia and the rats were then sacrificed. The test rat's eye that received ischemia was provided with a constant quantity $(4 \mathrm{ml})$ of XFZYD or the "same" volume of vehicle.
After anesthesia as described, the rats' pupils were dilated with 1\% tropicamide (Alcon, ZG, Switzerland) and 2.5\% phenylephrine (Akorn, Inc., IL, USA); in addition there was anesthesia of the ocular surface with $0.5 \%$ proparacaine (Alcon, ZG, Switzerland); then, a 30-gauge needle attached to a $25 \mu$ l syringe was used to perform the intravitreal injections. In certain instances, intravitreal injections $(5 \mu \mathrm{l})$ of $4 \mu \mathrm{M}$ Shikonin (Sigma-Aldrich, MO, USA), of $10 \mu \mathrm{M}$ JIB-04 (Sigma-Aldrich, MO, USA), of $100 \mathrm{mg} / 4 \mathrm{ml}$ Avastin (Hoffmann-La Roche, Basel, Switzerland) or of vehicle (an equal volume of dimethyl sulfoxide; J.T.Baker, NJ, USA) were given to ischemic eyes for fifteen minutes and retinal ischemia was induced by HIOP later.

\section{Flash ERG measurement}

Flash ERG was recorded on all animals before retinal ischemia (day 0) and after seven consecutive days of preischemia or postischemia administration of XFZYD or vehicle. The rats were kept in the dark for approximately $8 \mathrm{~h}$, then they were given mentioned anesthetics before the ERG measurements; for this, the pupils were dilated with $1 \%$ tropicamide and $2.5 \%$ phenylephrine (Akorn, Inc., IL, USA) as well as the ocular surface anesthetized with $0.5 \%$ proparacaine (Alcon, ZG, Switzerland). A light source was put $2 \mathrm{~cm}$ before the rat eye to achieve a stimulation of $0.5 \mathrm{~Hz}$. Fifteen continuous recordings were collected at $2-\mathrm{s}$ intervals and at $10 \mathrm{kHz}$; the amplification and the average of the responses were recorded using an amplifier P511/regulated power supply 107/ stimulator PS22 (Grass-Telefactor; AstroNova, QC, Canada). On a comparative basis, the b-wave quotient, i.e., the b-wave amplitude of the treated ischemic eye divided by the b-wave amplitude of the untreated fellow normal eye, was measured $[1,3]$. The animals with the b-wave ratios above $125 \%$ and below $75 \%$ were excluded.

\section{Measurement of fluorogold retrograde labeling RGCs}

Using the above anesthetics, a 2-cm incision was made in the rat's scalp and two small holes drilled in the skull as described previously [2]. Next, 5\% fluorogold (2 $\mu \mathrm{l}$; Sigma-Aldrich, MO, USA) were given by a microinjector at locations of $3.8,4.0$, and $4.2 \mathrm{~mm}$ down the skull. In all groups, the fluorogold injection was performed three days before the rats were sacrificed.

After sacrifice, retinal tissue was carefully isolated, incubated with $4 \%$ paraformaldehyde fixative, sectioned and processed as described previously [2]. The definition of mean RGC density was the total RGC amount divided by the whole retinal area [2].

\section{Cresyl violet staining}

The animals were sacrificed and injected with $0.9 \%$ saline $(w / v)$ into the cardiac cavity. Next, the eyeballs 
were enucleated, fixated with $4 \%(w / v)$ paraformaldehyde and embedded in paraffin (Tissue-Tek TEC 5; Sakura, Alphen aan den Rijn, Netherlands), then processed for sectioning $(5 \mu \mathrm{m})$. The sectioned retinal pieces were labeled with cresyl violet and evaluated under a light microscope (Leica, Heidelberg, Germany). Afterwards, the sectioned retinal pieces were photographed under the microscope with an identical magnifying power (Ilford Pan-F plus film, 50 ASA). Retinal layer thicknesses were calculated from the photographs.

To quantify the degree of retinal ischemic injury, we measured the whole retinal thicknesses [from the inner limiting membrane (ILM) to the retinal pigment epithelium (RPE) layer] and the inner retinal thicknesses [(from the ILM to the inner nuclear layer (INL)]. All measurements were carried out $1 \mathrm{~mm}$ from the optic nerve head. Three consecutive sectioned retinal pieces for each eye were measured to obtain a mean value. The laboratory researcher carrying out the measurements was masked to all information on the retinal sections when evaluating the changes in the thickness among the five groups, namely Sham, Vehicle $+\mathrm{I} / \mathrm{R}, \mathrm{XFZYD}_{1.35}+\mathrm{I} / \mathrm{R}$, $\mathrm{XFZYD}_{2.7}+\mathrm{I} / \mathrm{R}, \mathrm{I} / \mathrm{R}+\mathrm{XFZYD}_{2.7}$.

\section{Immunofluorescence analysis}

After sacrifice, the eyeballs were prepared in paraffin and processed for retinal sections described above. Next, the sectioned retinal pieces were immunohistochemically processed utilizing the following primary antibodies: goat anti-ChAT polyclonal antibody (Millipore, CA, USA), rabbit anti-GFAP polyclonal antibody (Millipore, CA, USA) and mouse anti-vimentin monoclonal antibody (Sigma-Aldrich, MO, USA). Thereafter, the retinal sections were soaked in the appropriate secondary antibodies: rhodamine-bound rabbit anti-goat antibody (Millipore, CA, USA), fluorescein isothiocyanate (FITC)-bound goat anti-rabbit IgG (Millipore, CA, USA) or FITC-bound goat anti-mouse IgG (Millipore, CA, USA). Simultaneously, the cellular nucleus was labeled with 4,6-diamidine-2phenylindole dihydrochloride (DAPI; EMD Chemicals, Darmstadt, Germany) as described previously [1, 24]. A fluorescence microscope was used to examine the sectioned retinal pieces as described previously $[1,24]$. To grade the immunoreactivity levels in the retinal sections among the various experimental groups, a researcher who was blinded to the status of the sections was requested to compare the immunoreactivity level of the various experimental groups against the sham group (control).

\section{Measurement of the concentrations of various mRNAs in the retina by rtPCR}

The mRNA concentrations of retinal VEGF, HIF- $1 \alpha$, PKM2 and RBP2 were measured by $\operatorname{rtPCR}[3,25]$. One day after a retinal ischemic insult and pre-/post-ischemia administration of the various compounds or after a sham process, the animals were sacrificed and the retinal tissues were dissected. Ultrasound emulsification was then performed in the presence of Tri Reagent (Sigma, Missouri, USA). Isolation of retinal RNA was carried out and first strand complementary DNA (cDNA) was synthesized after $2 \mu \mathrm{g}$ RQ1 RNase-Free DNase (0.05 U/ $\mu$ l; Promega)incubation utilizing High Capacity RNA-to-cDNA Master Mix (Applied Biosystems, MA, USA). Afterwards, the first-strand cDNA went through rtPCR; Fast Smart Quant Green Master Mix (Bio-protech, Gangwon-do, Korea) was used. The PCR was started by maintaining at $95{ }^{\circ} \mathrm{C}$ for $20 \mathrm{~s}$ and, subsequently, 40 rounds of $95^{\circ} \mathrm{C}$ for $3 \mathrm{~s}$ and $60{ }^{\circ} \mathrm{C}$ for $30 \mathrm{~s}$ were carried out. Cycling was performed on a StepOne Plus ${ }^{\text {Th }}$ Real-Time PCR System (Applied Biosystems, MA, USA). Measurement of the relative level of a target mRNA (a comparative assay) was carried out utilizing the cytoskeleton gene $\beta$-actin as the internal control. This procedure allowed the measurement of the normalized level of the target mRNA and considers the differences in the quantity of total mRNA applied to each reaction $(\Delta \mathrm{Ct}=\mathrm{Ct}$ target-Ct $\beta$-actin; cycle threshold, Ct). The relative VEGF/HIF-1 $\alpha /$ PKM2/ RBP2 level differences caused by ischemia or the sham process were measured as fold variations relative to the contralateral untreated control normal retina using the calibration equation ( $\mathrm{Ct}=\Delta \mathrm{Ct}$ induced- $\Delta \mathrm{Ct}$ normal). Relative gene expression was measured using the $2^{-\Delta \Delta \mathrm{Ct}}$ equation, as mentioned in the company procedures [3, 25]. The results retrieved for each experimental procedure were collected together, and a total ratio difference related with the Sham (control) was calculated. Table 1 describes the PCR oligonucleotide primers used for the rtPCR (Mission Biotech Co. Ltd., Taipei, Taiwan).

\section{Measurement of the protein levels by the western blot method}

One day after a retinal ischemic insult and pre-/postischemia administration of the mentioned compounds or after a sham procedure, the animals were sacrificed. The retinal tissues were isolated and emulsified using ultrasound in lysis buffer, namely mammalian protein extraction reagent (HyCell, Taipei, Taiwan). The same quantities of denatured protein $(100 \mu \mathrm{g} / 32 \mu \mathrm{l} /$ well $)$ were separated on a $\mathrm{NuPAGE}^{\circ}$ Tris-Acetate mini gel electrophoresis system (Invitrogen, MA, USA) using a $3 \sim 8 \%$ separating gel and a $3.2 \%$ stacking gel as described previously $[7,25]$. The separated proteins were transferred to a polyvinylidene difluoride $(P V D F)$ membrane (Millipore, MA, USA). Next, the membranes were blocked with 5\% fat-free skimmed milk (Fonterra, Taoyuan, Taiwan) in phosphate-buffered saline (PBS) for $1 \mathrm{~h}$ at room temperature. 
Table 1 Sequences of oligonucleotide primers and details of polymerase chain reactions

\begin{tabular}{|c|c|c|c|c|c|}
\hline mRNA & $\begin{array}{l}\text { Primers }\left(5^{\prime} \rightarrow 3^{\prime}\right) \\
\text { F: Forward } \\
\text { R: Reverse }\end{array}$ & Bases in base pairs & Product size & $\begin{array}{l}\text { Cycles profile } \\
\text { Denaturation/annealing/extension } \\
\text { (Temperature and time in seconds) }\end{array}$ & Cycles number \\
\hline \multirow[t]{2}{*}{$\beta$-actin } & F: AGGGAAATCGTGCGTGACAT & 694713 & 150 & $95^{\circ} \mathrm{C} / 95^{\circ} \mathrm{C} / 60^{\circ} \mathrm{C}$ & 40 \\
\hline & R: GAACCGCTCATTGCCGATAG & $824-843$ & & $(20 s / 3 s / 30 s)$ & \\
\hline \multirow[t]{2}{*}{ VEGF } & F: GCGGGCTGCTGCAATG & $1262-1277$ & 268 & $95^{\circ} \mathrm{C} / 95^{\circ} \mathrm{C} / 60^{\circ} \mathrm{C}$ & 40 \\
\hline & R: TGCAACGCGAGTCTGTGTTT & $1528-1547$ & & $(20 s / 3 s / 30 s)$ & \\
\hline \multirow[t]{2}{*}{ HIF-1a } & F: ACAGCTCCCCAGCATTTCAC & $2748-2767$ & 90 & $95^{\circ} \mathrm{C} / 95^{\circ} \mathrm{C} / 60^{\circ} \mathrm{C}$ & 40 \\
\hline & R: GGACAAACTCCCTCACCAAAAA & $2837-2816$ & & $(20 s / 3 s / 30 s)$ & \\
\hline \multirow[t]{2}{*}{ PKM2 } & F: TCTACGTGGACGATGGGCT & $833-851$ & 403 & $95^{\circ} \mathrm{C} / 95^{\circ} \mathrm{C} / 60^{\circ} \mathrm{C}$ & 40 \\
\hline & R: AGGAAGACCTTCTCTGCCGGA & $1215-1235$ & & $(20 s / 3 s / 30 s)$ & \\
\hline \multirow[t]{2}{*}{ RBP2 } & F: TTGTGGTGACGTTTCCTCGT & $2093-2112$ & 213 & $95^{\circ} \mathrm{C} / 95^{\circ} \mathrm{C} / 60^{\circ} \mathrm{C}$ & 40 \\
\hline & R: CAGCCAGCCCCACATCTAAG & $2305-2286$ & & $(20 s / 3 s / 30 s)$ & \\
\hline
\end{tabular}

The blots were then soaked one night at $4{ }^{\circ} \mathrm{C}$ in the following primary antibodies, namely, mouse monoclonal anti- $\beta$-actin antibody (1:80,000, Novusbio, MA, USA), mouse monoclonal anti-VEGF antibody (1:200, Novusbio, MA, USA), mouse monoclonal anti-HIF-1 $\alpha$ antibody (1:1000, Abcom, Cambridge, UK), rabbit polyclonal antiPKM2 antibody (1:600, Abcom, Cambridge, UK) and rabbit monoclonal anti-RBP2 antibody (1:500, Abcom, Cambridge, UK). Next, the blots were soaked in the appropriate secondary antibody, either horseradish peroxidasebound goat anti-rabbit or horseradish peroxidase-bound goat anti-mouse IgG (1:2000 or $1: 10,000$, respectively, Santa Cruz Biotechnology, TX, USA) at $37{ }^{\circ} \mathrm{C}$ for $1 \mathrm{~h}$. The primary/secondary antibodies were diluted in $5 \%$ fat-free skimmed milk. Finally, the membranes were developed using an enhanced chemiluminescent analysis system (HyCell, Taipei, Taiwan), which was followed by exposure to an X-ray film (Fujifilm, Tokyo, Japan). Analysis of the quantity of the each protein was carried out by scanning densitometry.

\section{Analytical statistics}

The results are presented as the mean \pm standard deviation (SD). One-way analysis of variance (ANOVA) followed by the Dunnett's test was performed to compare the results. A $p$ value of $<0.05$ was defined as statistical significance. Sigma Plot 12.5 (Systat Software, CA, USA) was used to analyze the data and draw the quantitative plots.

\section{Results}

The influence of XFZYD on ERG b-wave amplitude

In the retina subjected to the sham procedure (Sham, Fig. 1), the ERG b-wave amplitude was measured as $0.36 \mathrm{mV}$. After retinal $\mathrm{I} / \mathrm{R}$, the $\mathrm{b}$-wave amplitude was reduced to a considerable extent. The reduction was not affected by preischemia or postischemia administration of vehicle (Vehicle + I/R: $0.01 \mathrm{mV}$, Fig. 1a; I/R + Vehicle: $0.02 \mathrm{mV}$, Fig. 1b). Nevertheless, preischemia XFZYD administration $\left(X^{2} Z Y_{1.35}+\mathrm{I} / \mathrm{R}, 1.35 \mathrm{~g} / \mathrm{kg} /\right.$ day; $\mathrm{XFZYD}_{2.7}+\mathrm{I} / \mathrm{R}, 2.7 \mathrm{~g} / \mathrm{kg} /$ day, Fig. 1a) and postischemia XFZYD administration (I/R + XFZYD $1.35,1.35 \mathrm{~g} / \mathrm{kg} /$ day; $\mathrm{I} / \mathrm{R}+\mathrm{XFZYD}_{2.7}, 2.7 \mathrm{~g} / \mathrm{kg} /$ day, Fig. 1b) mitigated the ischemia-associated reduction in b-wave and the amplitudes were elevated to $0.03,0.13,0.02$ and $0.10 \mathrm{mV}$, respectively.

As shown in Fig. 1c $(n=4 \sim 9)$, as compared to the sham group $(1.00 \pm 0.21)$, the $b$-wave ratio was significantly $(p<0.001)$ reduced in the Vehicle $+\mathrm{I} / \mathrm{R}$ group $(0.03 \pm 0.02)$. Of note, after preischemia XFZYD administration, a dose-responsive (1.35 vs. $2.7 \mathrm{~g} / \mathrm{kg} /$ day) and significant (at $1.35 \mathrm{~g} / \mathrm{kg} /$ day, $p=0.04$; at $2.7 \mathrm{~g} / \mathrm{kg} /$ day, $p<0.001)$ mitigation was detected in the ischemiainduced b-wave ratio reduction after $\mathrm{I} / \mathrm{R}\left(\mathrm{XFZYD}_{1.35}+\mathrm{I} / \mathrm{R}\right.$ vs. $\mathrm{XFZYD}_{2.7}+\mathrm{I} / R=0.18 \pm 0.16$ vs. $\left.0.43 \pm 0.21\right)$.

Again, in Fig. 1d ( $n=5 \sim 9)$, as compared to the sham group $(1.00 \pm 0.21)$, the $b$-wave ratio was significantly $(p<0.001)$ reduced in the $\mathrm{I} / \mathrm{R}+$ Vehicle group $(0.10 \pm 0.07)$. Notably, after postischemia XFZYD administration, there was also a dose-responsive (at $1.35 \mathrm{~g} / \mathrm{kg}$ / day; $0.10 \pm 0.10 ; p=0.91$ ) and significant (at $2.7 \mathrm{~g} / \mathrm{kg} /$ day; $0.33 \pm 0.11 ; p=0.003$ ) counteraction of the ischemiaassociated b-wave ratio reduction.

On the other hand, the ERG b-wave ratios of the sham eye $(n=9)$ did not significantly $(p=0.86)$ differ from those of the normal eye $(n=5 ; 1.03 \pm 0.35)$.

\section{The effect of XFZYD on the density of retrograde fluorogold labeled RGCs}

As shown in Fig. 2, the density of RGCs in the sham retina (Sham, Fig. 2a and f) was $366.78 \pm 10.30$ cells/field. Compared to the Sham retina, the density of RGCs was significantly $(p<0.001)$ reduced to $131.83 \pm 9.78$ cells/ field in rats subjected to retinal ischemia and preischemia 


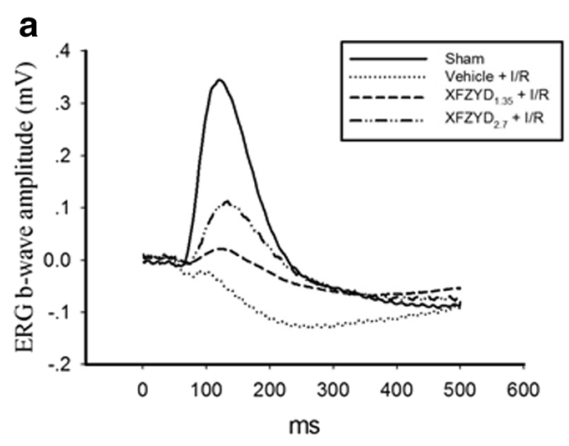

C

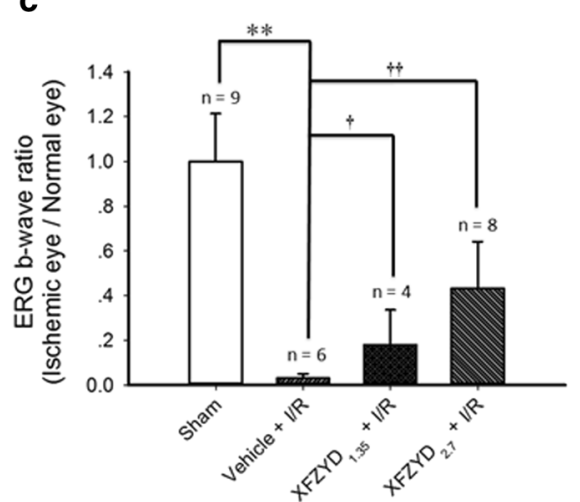

b

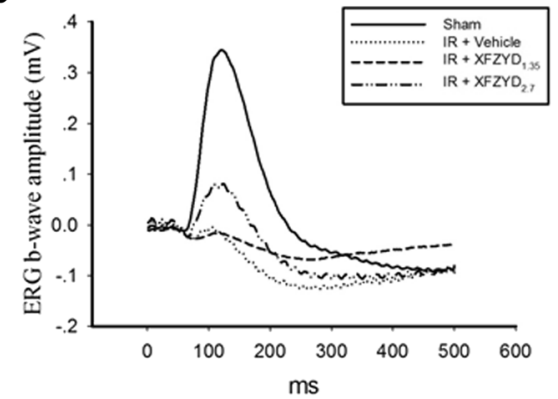

d

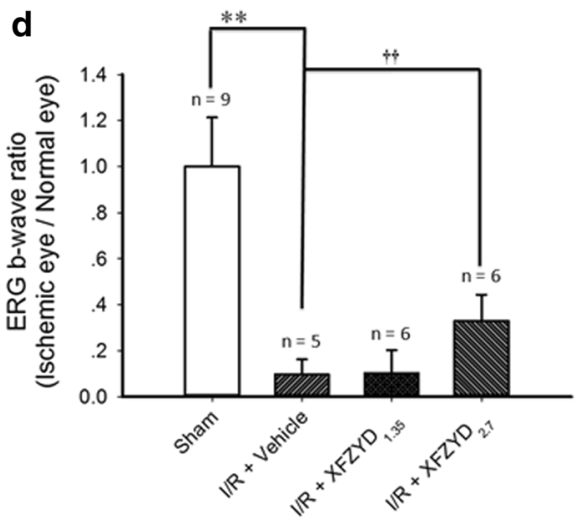

Fig. 1 Electroretinogram (ERG): the influence of preischemia administration or postischemia administration of XFZYD on retinal ischemia. In comparison with the sham retina (Sham), the b-wave amplitude was considerably reduced after pressure-induced retinal ischemia plus reperfusion and preischemia administration (Vehicle $+\mathrm{I} / \mathrm{R} ; 1 \mathbf{a})$ or postischemia administration of Vehicle $(I / R+$ Vehicle; $1 \mathbf{b})$ in a representative rat. This reduction was attenuated dose-dependently by preischemia administration (at $1.35 \mathrm{~g} / \mathrm{kg} /$ day, $X F Z Y D_{1.35}+\mathrm{l} / \mathrm{R}$; at $2.7 \mathrm{~g} / \mathrm{kg} /$ day, $X F Z Y D_{2.7}+\mathrm{I} / \mathrm{R}$, 1a) or postischemia administration of XFZYD (at $1.35 \mathrm{~g} / \mathrm{kg} /$ day, I/R + XFZYD 1.35 ; at $2.7 \mathrm{~g} / \mathrm{kg} /$ day, I/R + XFZYD $2.7,1 \mathbf{b}$ ) in one animal of each relevant group. As compared with the Sham group, a significant (**, $p<0.01$ ) decrease in b-wave ratio was revealed for the Vehicle $+\mathrm{I} / \mathrm{R}(\mathbf{1} \mathbf{c})$ or $\mathrm{I} / \mathrm{R}+$ Vehicle (1d) group following pressure-induced retinal ischemia. This ischemia-induced decrease was alleviated in a dose responsive and significant manner (,$+ p<0.05 ;+\dagger$, $p<0.01,1 \mathbf{c})$ by the preischemia administration of 1.35 and $2.7 \mathrm{~g} / \mathrm{Kg} /$ day of XFZYD. Postischemia administration of XFZYD at $2.7 \mathrm{~g} / \mathrm{Kg} / \mathrm{day}(1 \mathbf{d})$ also significantly $(+\dagger, p<0.01)$ alleviated the reduction. The data are shown as mean values \pm SD. XFZYD, Xue-Fu-Zhu-Yu decoction

administration of vehicle (Vehicle $+\mathrm{I} / \mathrm{R}$, Fig. $2 \mathrm{~b}$ and $\mathrm{f}$ ). Moreover, this reduction was dose-responsively and significantly $(p<0.001)$ attenuated (with a smaller influence at $1.35 \mathrm{~g} / \mathrm{kg} /$ day) when the rats were subjected to retinal ischemia and preadministrated with 1.35 and $2.7 \mathrm{~g} / \mathrm{Kg} /$ day XFZYD (XFZYD ${ }_{1.35}+$ I/R, Fig. $2 \mathrm{c}$ and f: $191.38 \pm 9.45$ cells/field; XFZYD $2.7+$ I/R, Fig. $2 d$ and f: $276.33 \pm 12.11$ cells/field). Postischemia administration of $2.7 \mathrm{~g} / \mathrm{Kg} /$ day XFZYD also significantly $(p<0.001)$ attenuated this ischemia-induced reduction $\left(\mathrm{I} / \mathrm{R}+\mathrm{XFZYD}_{2.7}\right.$, Fig. $2 \mathrm{e}$ and $\mathrm{f}$ : $227.58 \pm 11.60$ cells/field). The area of one field is approximately $0.25 \mathrm{~mm}^{2}$.

\section{The influence of XFZYD on the thickness of the different retinal layers labelled with cresyl violet}

Figure 3 shows the results of retinal sections obtained from the same distance (1 $\mathrm{mm}$ from optic nerve head) across the five groups $(n=4)$. As compared with the retina subjected to the sham procedure (Sham, Fig. 3a and f: $176.0 \pm 14.81 \mu \mathrm{m}$ for the whole retina, $99.50 \pm 11.33 \mu \mathrm{m}$ for the inner retina), following $I / R$ and preadministrating the rats with vehicle, the thickness of the whole retina and the inner retina (Vehicle $+I / R$, Fig. $3 b$ and $\mathrm{f}$ : $103.00 \pm 6.88 \mu \mathrm{m}$ for the whole retina, $46.75 \pm$ $7.27 \mu \mathrm{m}$ for the inner retina) were significantly $(p<0.001)$ reduced. Moreover, the decrease was dosedependently (with a smaller influence at $1.35 \mathrm{~g} / \mathrm{kg} /$ day) and significantly attenuated when the rats were subjected to $\mathrm{I} / \mathrm{R}$ and preadministrated with 1.35 and $2.7 \mathrm{~g} / \mathrm{Kg} /$ day XFZYD [XFZYD ${ }_{1.35}+\mathrm{I} / \mathrm{R}$, Fig. $3 \mathrm{c}$ and $\mathrm{f}$ : $123.25 \pm 8.62 \mu \mathrm{m}$ for the full-thickness retina $(p=0.01), 57.75 \pm 5.06 \mu \mathrm{m}$ for the inner retina $(p=0.048) ; \mathrm{XFZYD}_{2.7}+\mathrm{I} / \mathrm{R}$, Fig. $3 \mathrm{~d}$ and $\mathrm{f}$ : $144.00 \pm 8.83 \mu \mathrm{m}$ for the whole retina $(p<0.001)$, $67.75 \pm 8.18 \mu \mathrm{m}$ for the inner retina $(p=0.009)]$. Postischemia administration of $2.7 \mathrm{~g} / \mathrm{Kg} /$ day XFZYD also significantly attenuated this ischemia-induced decrease $\left[\mathrm{I} / \mathrm{R}+\mathrm{XFZYD}_{2.7}\right.$, Fig. $3 \mathrm{e}$ and $\mathrm{f}: 130.25 \pm 9.98 \mu \mathrm{m}$ for the full-thickness retina $(p=0.004), 63.50 \pm 6.95 \mu \mathrm{m}$ for the inner retina $(p=0.016)]$. 

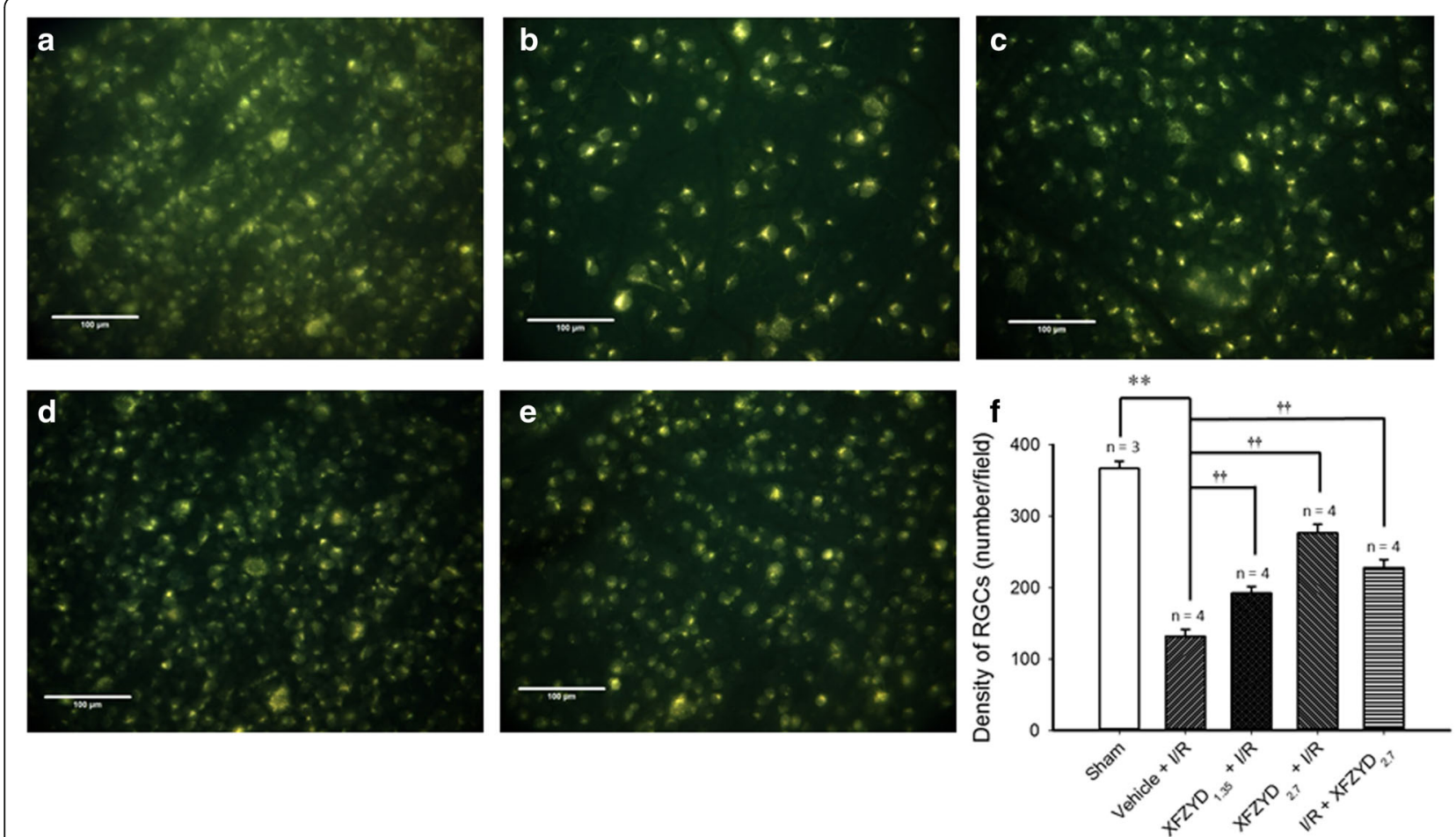

Fig. 2 Retrograde staining with fluorogold. The micrographs revealed the density of retinal ganglion cells (RGCs) after the sham process (a, Sham), ischemia plus reperfusion (I/R) with preadministered vehicle (b, Vehicle + I/R), preadministered XFZYD at $1.35 \mathrm{~g} / \mathrm{kg} /$ day $\left(\mathbf{c}, \mathrm{XFZYD}_{1.35}+\mathrm{I} / \mathrm{R}\right)$,

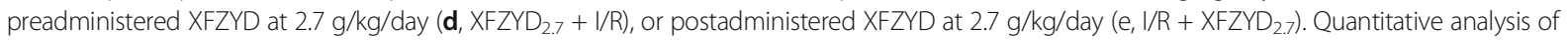
the density of RGCS is shown (f). The mean values \pm SD $(n=3 \sim 4)$ was shown for each bar. ${ }^{* *}$ represents a significant difference $(p<0.01$; Sham

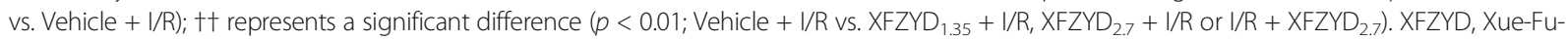
Zhu-Yu decoction. Scale bars $=100 \mu \mathrm{m}$

\section{The influence of XFZYD on ChAT immunolabeling}

As demonstrated in Fig. 4, in the retina subjected to the sham procedure (Sham, Fig. 4b), ChAT-immunopositive (red) amacrine cell bodies (arrow heads; Fig. 4g: $22.75 \pm 2.50$ /field) in the INL and the ganglion cell layer (GCL); and their neuronal fibers formed two welldefined strata (arrows) in the inner plexiform layer. In the ischemic retina preadministrated with vehicle (Vehicle + I/R; Fig. 4c), there was a significantly $(p<0.001)$ smaller number of the ChAT-immunopositive amacrine cell bodies (Fig. 4g: $9.25 \pm 1.50 /$ field) after retinal I/R and preischemia administration of vehicle; moreover, the IPL immunoreactivity of these cells was drastically decreased. Clinically and importantly, these alterations were dose-responsively and significantly alleviated in the ischemic retinas when 1.35 and $2.7 \mathrm{~g} / \mathrm{Kg} /$ day XFZYD were preadministrated $\left(X X_{2 Y D} D_{1.35}+I / R\right.$, Fig. $4 d$ and g: $14.75 \pm 2.75 /$ field, $p=0.013)$; XFZYD $2.7+\mathrm{I} / \mathrm{R}$, Fig. $4 \mathrm{e}$ and g: $20.50 \pm 2.08$ /field, $p<0.001)$. Postischemia administration of $2.7 \mathrm{~g} / \mathrm{Kg} /$ day XFZYD $\left(\mathrm{I} / \mathrm{R}+\mathrm{XFZYD}_{2.7}\right.$; Fig. 4f and g: $16.25 \pm 3.86 /$ field; $p=0.015$ ) also clearly attenuated these ischemia-induced alterations. DAPI (blue, Fig 4a) was used to label the cellular nucleus in the Sham retina. The area of one field is approximately $0.25 \mathrm{~mm}^{2}$.

\section{The effect of XFZYD on GFAP or Vimentin immunolabeling}

As demonstrated in Fig. 5, in the Sham retina (Fig. 5b), the Müller cells could be identified using the GFAP immunolabelings at the end feet (arrow head) in the GCL and at the processes that extended into the IPL, INL and ONL (arrows). In the ischemic retina preadministrated with vehicle (Vehicle $+I / R$, Fig. $5 \mathrm{c}$ ), the anti-GFAP immuolabeling was enhanced. Moreover, this alteration was clearly and dose-dependently mitigated in the ischemic retinas preadministrated with 1.35 and $2.7 \mathrm{~g} / \mathrm{Kg} /$ day XFZYD $\left(X\right.$ ZZY $_{1.35}+\mathrm{I} / \mathrm{R}$, Fig. 5d; $\mathrm{XFZYD}_{2.7}+\mathrm{I} / \mathrm{R}$, Fig. 5e). Postischemia administration of $2.7 \mathrm{~g} / \mathrm{Kg} /$ day XFZYD (I/R + XFZYD ${ }_{2.7}$, Fig. 5f) also clearly attenuated this ischemia-induced alteration.

In comparison to the control retina (Sham, Fig 6b), anti-vimentin immunoreactivity was also enhanced after retinal ischemia and preischemia administration of vehicle (Vehicle + I/R, Fig 6c). This enhancement was drastically and in a dose-responsive manner counteracted by preischemia administration of 1.35 and $2.7 \mathrm{~g} / \mathrm{Kg} /$ day XFZYD $\left(X_{Z Z Y D} .35+I / R\right.$, Fig. 6d; XFZYD $2.7+I / R$, Fig 6e). Postischemia administration of $2.7 \mathrm{~g} / \mathrm{Kg} /$ day XFZYD $\left(\mathrm{I} / \mathrm{R}+\mathrm{XFZYD}{ }_{2.7}\right.$, Fig $\left.6 \mathrm{f}\right)$ also considerably obliterated 


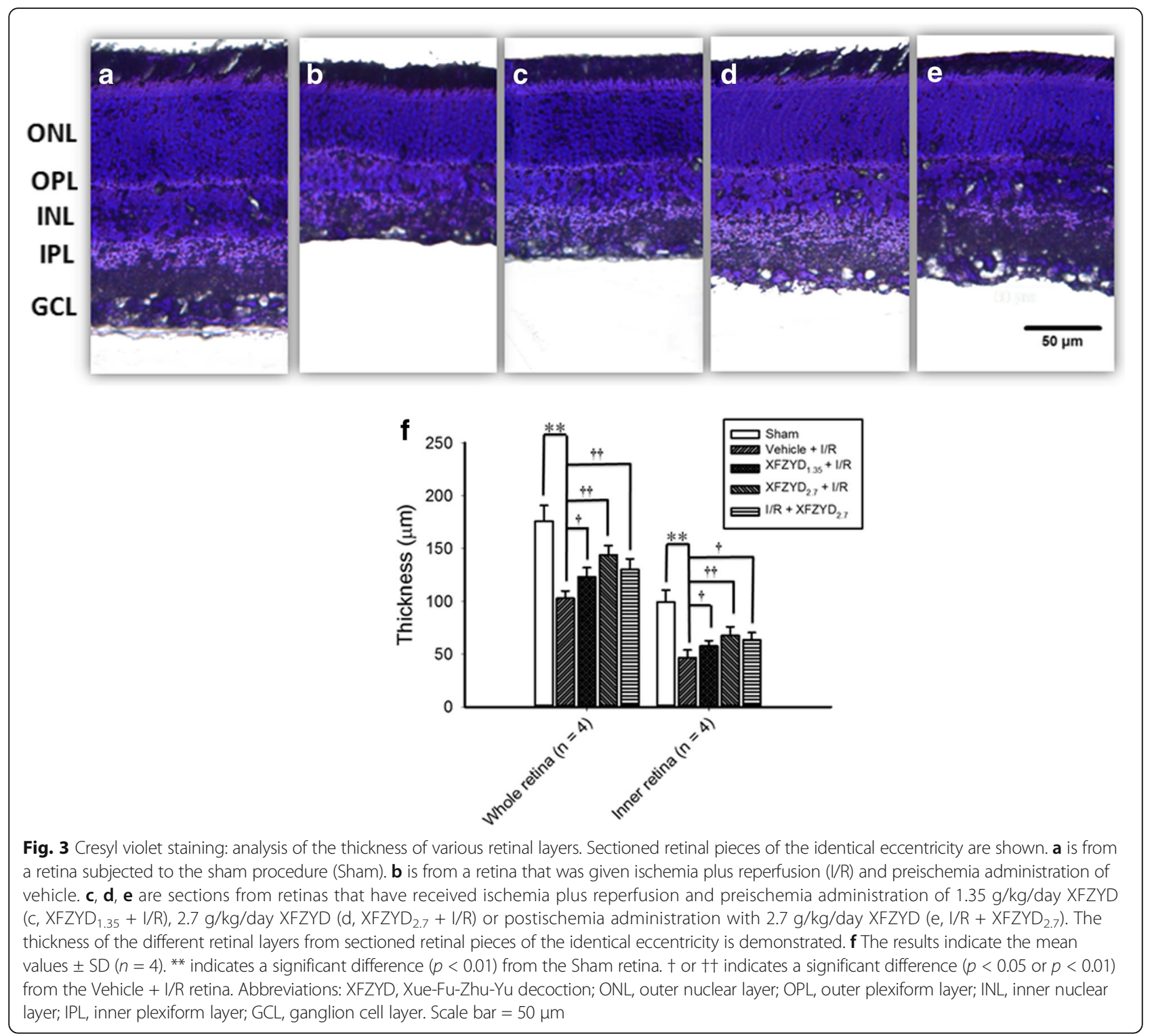

this ischemia-induced alteration. DAPI (blue; Figs. 5a and 6a) was used to label the cellular nucleus of the Sham retina.

\section{The influence of XFZYD on the mRNA levels of VEGF,} HIF-1a, PKM2 and RBP2 in the retina

As demonstrated in Fig. $7(n=4)$, in contrast with the control retina (Sham; VEGF $=1.06 \pm 0.13$, HIF-1 $\alpha=$ $0.92 \pm 0.10$, PKM2 $=1.10 \pm 0.33, \mathrm{RBP} 2=1.09 \pm 0.56)$, the ratios for VEGF (A), HIF-1 $\alpha$ (B), PKM2 (C) and RBP2 (D) in the ischemic retina preadministrated with vehicle (Vehicle $+\mathrm{I} / \mathrm{R}$; VEGF $=3.62 \pm 0.33$, HIF$1 \alpha=3.29 \pm 0.24$, PKM2 $=11.25 \pm 0.71, \mathrm{RBP} 2=11.80 \pm 3.14)$ were significantly $(p<0.001)$ elevated. Moreover, this enhancement was dose-dependently (with a smaller influence at $1.35 \mathrm{~g} / \mathrm{kg} /$ day) and significantly $\left[\right.$ XFZYD $_{1.35}+\mathrm{I} / \mathrm{R}(\mathrm{VEGF}=2.2 \pm 0.55, p=0.005$; HIF$1 \alpha=2.30 \pm 0.55, p=0.016 ;$ PKM2 $=7.11 \pm 0.93$, $p<0.001 ; \mathrm{RBP} 2=5.80 \pm 2.37, p=0.023) ; \mathrm{XFZYD}_{2.7}+\mathrm{I} / \mathrm{R}$ $(\mathrm{VEGF}=1.7 \pm 0.38, \quad$ HIF-1 $\alpha=1.65 \pm 0.12$, PKM2 $=2.32 \pm 0.51, p<0.001 ; \mathrm{RBP} 2=2.39 \pm 0.77$, $p=0.001)$ ] counteracted in ischemic retinas preadministrated with 1.35 and $2.7 \mathrm{~g} / \mathrm{Kg} /$ day XFZYD. Postischemia administration of $2.7 \mathrm{~g} / \mathrm{Kg} /$ day XFZYD also significantly $\left[\mathrm{I} / \mathrm{R}+\mathrm{XFZYD}_{2.7} \quad(\mathrm{VEGF}=1.90 \pm 0.34 ;\right.$ HIF$1 \alpha=1.87 \pm 0.22 ;$ PKM2 $=5.86 \pm 0.95, p<0.001$; $\mathrm{RBP} 2=5.19 \pm 1.17, p=0.008)]$ mitigated this ischemiainduced increase.

In addition, when the retinal mRNA concentrations of VEGF, HIF-1 $\alpha$, PKM2 and RBP2 were compared, no 


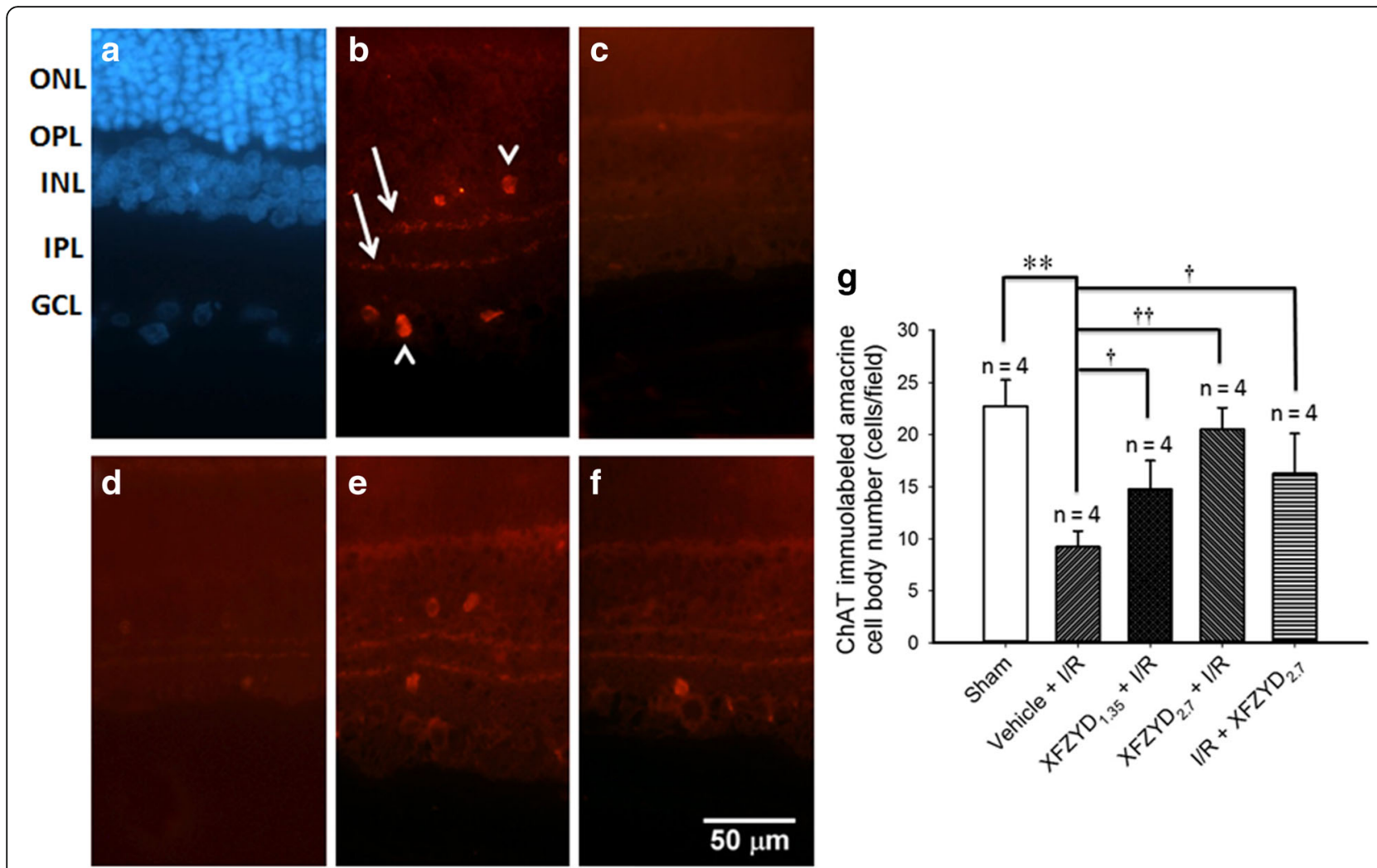

Fig. 4 Choline acetyltransferase (ChAT, red) immunohistochemistry. a is the retina subjected to the sham procedure (Sham) and the cellular nucleus is labeled with 4,6-diamidine-2-phenylindole dihydrochloride (DAPI, blue). b shows the amacrine cell bodies (Sham; arrow heads) located in the INL and the GCL and their neuronal fibers (arrows); these demonstrate two distinct bands in the IPL. $\mathbf{c}$ is from the retina that received I/R and preischemia administration of vehicle; there is a drastic decrease in the IPL immunolabelling as well as the amacrine cell body number. $\mathbf{d}$, e, $\mathbf{f}$ are sections from the retinas that received I/R and preischemia administration of $1.35 \mathrm{~g} / \mathrm{kg} /$ day XFZYD (d, XFZYD $1.35+\mathrm{l} / \mathrm{R}), 2.7 \mathrm{~g} / \mathrm{kg} /$ day XFZYD (e, XFZYD $2.7+\mathrm{l} / \mathrm{R})$ or postischemia administration of $2.7 \mathrm{~g} / \mathrm{kg} /$ day XFZYD $\left(\mathbf{f}, 1 / R+X F Z Y D_{2.7}\right)$. Moreover, these ischemia-induced alterations were clearly and dose-dependently alleviated when the ischemic retinas were preadministrated with 1.35 and $2.7 \mathrm{~g} / \mathrm{Kg} /$ day XFZYD. Postischemia administration of $2.7 \mathrm{~g} / \mathrm{Kg} / \mathrm{day}$ XFZYD also clearly attenuated these ischemia-induced alterations. Each bar represents the mean values $\pm S D(n=4)$ following the sham procedure or $\mathrm{l} / \mathrm{R}(\mathbf{g})$. ** indicates significance $(p<0.01$; Sham vs. Vehicle $+I / R)$. † or t+ indicates significance $(p<0.05$ or $p<0.01$; Vehicle $+I / R$ vs. XFZYD $1.35+I / R$,

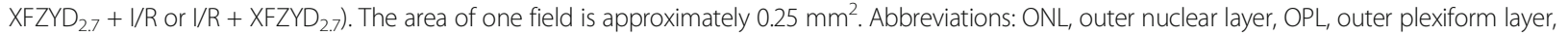
INL, inner nuclear layer, IPL, inner plexiform layer, GCL, ganglion cell layer. XFZYD, Xue-Fu-Zhu-Yu decoction. Scale bar $=50 \mu \mathrm{m}$

significant difference existed between the sham eye and the normal eye $(n=4$; VEGF $=1.02 \pm 0.11, p=0.36$; HIF- $1 \alpha=1.00 \pm 0.03, p=0.20 ;$ PKM2 $=1.02 \pm 0.13$, $p=0.36 ; \mathrm{RBP} 2=1.00 \pm 0.04, p=0.39)$.

\section{The influence of XFZYD on the concentrations of various proteins in the retina}

As demonstrated in Fig. 8a and c $(n=4$ for VEGF, HIF- $1 \alpha$ and PKM2; $n=3$ for RBP2), in contrast to the control retina (Sham; VEGF, HIF-1 $\alpha$, PKM2 and RBP2 $=1.00)$, after $I / R$ and preischemia administration of vehicle $(\mathrm{VEGF}=5.31 \pm 0.53$, HIF- $1 \alpha=3.10 \pm 0.40$, PKM2 $=4.51 \pm 0.60, \mathrm{RBP} 2=11.92 \pm 3.22)$, there was a significant $(n=4$, VEGF, HIF- $1 \alpha$ and PKM2, $p<0.001$; $n=3$, RBP2, $p=0.004$ ) increase in the protein ratios for VEGF, HIF-1 $\alpha$, PKM2 and RBP2. Moreover, this enhancement was dose-dependently (with a smaller influence at $1.35 \mathrm{~g} / \mathrm{kg} /$ day) and significantly $\left[\mathrm{XFZYD}_{1.35}+\mathrm{I} / \mathrm{R}\right.$
$(\mathrm{VEGF}=3.31 \pm 1.54, p=0.049 ; \mathrm{HIF}-1 \alpha=1.71 \pm 0.92$, $p=0.032 ; \quad \mathrm{PKM} 2=2.88 \pm 0.98, p=0.022$; $\mathrm{RBP} 2=4.46 \pm 3.35, p=0.049 ; \mathrm{XFZYD}_{2.7}+\mathrm{I} / \mathrm{R}$ $(\mathrm{VEGF}=2.52 \pm 1.35, p=0.008$; HIF- $1 \alpha=1.16 \pm 0.36$, PKM2 $=1.56 \pm 0.53, p<0.001 ; \mathrm{RBP} 2=1.00 \pm 0.59$, $p=0.004)]$ mitigated when the ischemic retinas were preadministrated with 1.35 and $2.7 \mathrm{~g} / \mathrm{Kg} /$ day XFZYD. Postischemia administration of $2.7 \mathrm{~g} / \mathrm{Kg} /$ day XFZYD also significantly $\left(\mathrm{I} / \mathrm{R}+\mathrm{XFZYD}_{2.7}:\right.$ VEGF $=2.91 \pm 1.59$, $p=0.029$; HIF- $1 \alpha=1.57 \pm 0.61, p=0.006$; PKM2 = $2.62 \pm 0.49, p=0.002 ; \mathrm{RBP} 2=1.42 \pm 0.52, p=0.005)$ attenuated this ischemia-induced increase. In addition (Fig. $8 \mathrm{~b}$ and d), significant attenuation of the ischemiainduced increase in the ratio of VEGF (Vehicle $=6.92 \pm 1.55$; Shikonin $=1.84 \pm 0.60, p=0.018$; JIB-04 $=1.68 \pm 0.46$, $p=0.016$; Avastin $=1.08 \pm 0.23, p=0.01)$, HIF $-1 \alpha$ $($ Vehicle $=3.69 \pm 0.22$; Shikonin $=1.95 \pm 0.76, p=0.007$; JIB-04 $=2.14 \pm 1.11, p=0.04$; Avastin $=3.65 \pm 0.84$, 

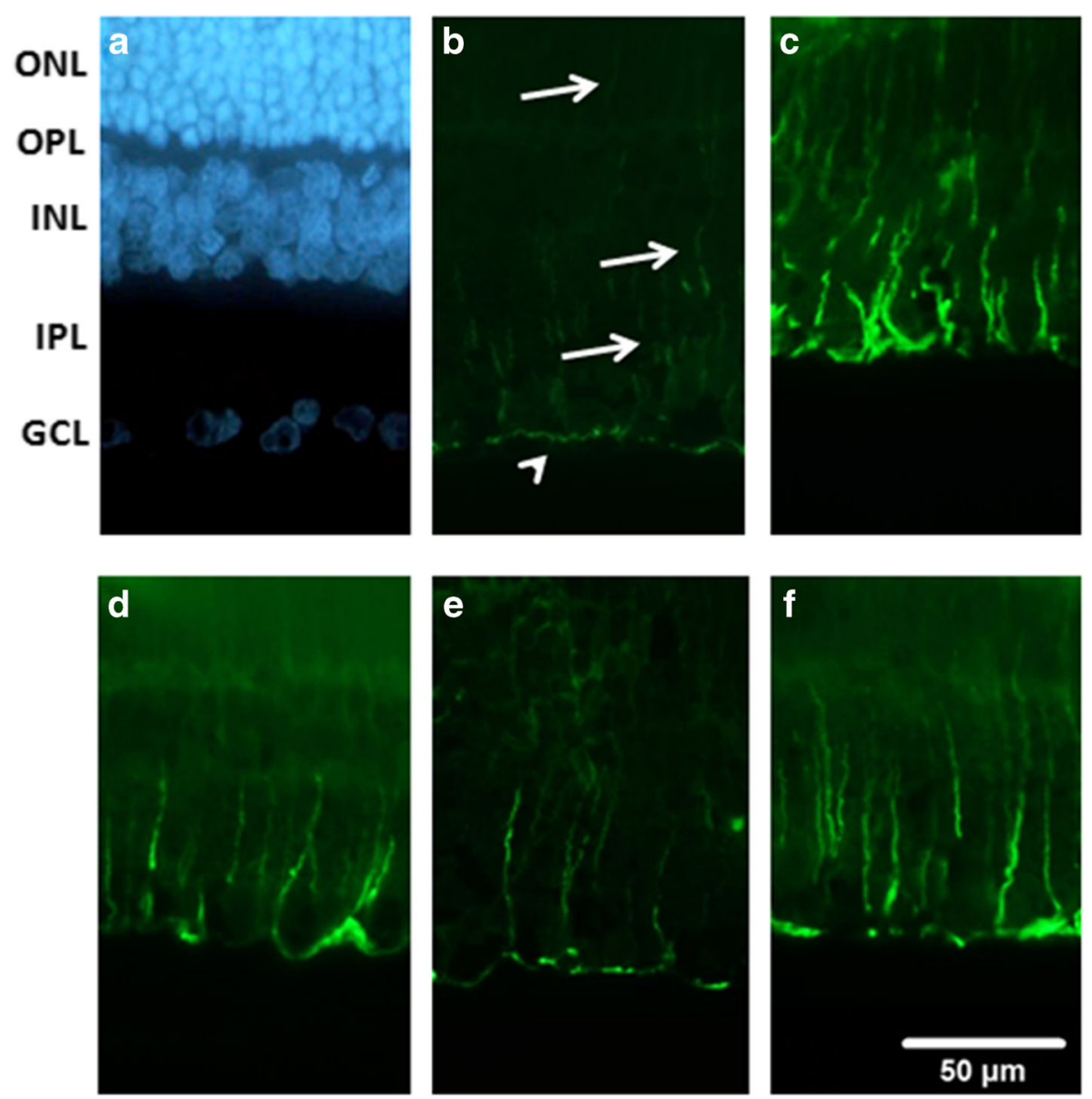

Fig. 5 Glial fibrillary acidic protein (GFAP, green) immunohistochemistry. a is the cellular nucleus of the sham retina labeled with 4,6-diamidine-2phenylindole dihydrochloride (DAPI, blue); b shows Müller cells labelled with GFAP immunoreactivity at the end feet (arrow head) in the GCL and at the processes in the IPL, INL and ONL (arrows). c shows a retina that received I/R and preischemia adminstration of vehicle; there is an increase in anti-GFAP immuolabeling. (d, e, $\mathbf{f}$ ) are sections from the retinas that received I/R and preischemia administration of $1.35 \mathrm{~g} / \mathrm{kg} / \mathrm{day}$ XFZYD (d, XFZYD $1.35+$ I/R), $2.7 \mathrm{~g} / \mathrm{kg} /$ day XFZYD $\left(\mathbf{e}\right.$, XFZYD $\left._{2.7}+\mathrm{I} / \mathrm{R}\right)$ or postischemia administration of $2.7 \mathrm{~g} / \mathrm{kg} /$ day XFZYD $\left(\mathbf{f}, 1 / R+\mathrm{XFZYD}_{2.7}\right)$. Moreover, this ischemia-associated alteration was obviously and dose-dependently mitigated as ischemic retinas were preadministrated with 1.35 and $2.7 \mathrm{~g} / \mathrm{Kg} /$ day XFZYD. Postischemia administration of $2.7 \mathrm{~g} / \mathrm{Kg} /$ day XFZYD also obviously mitigated this ischemia-induced alteration. ONL: outer nuclear layer, OPL: outer plexiform layer, INL: inner nuclear layer, IPL: inner plexiform layer, GCL: ganglion cell layer. Scale bar $=50 \mu \mathrm{m}$

$p=0.942)$, PKM2 (Vehicle $=4.04 \pm 0.50$; Shikonin $=$ $0.61 \pm 0.19, p<0.001$; JIB-04 = $1.67 \pm 1.31, p=0.028$; Avastin $=3.42 \pm 0.88, p=0.390)$, and RBP2 $($ Vehicle $=7.77 \pm 2.27$; Shikonin $=1.00 \pm 0.71$, $p=0.043$; JIB-04 $=1.16 \pm 0.14, p=0.044$; Avastin $=$ $6.00 \pm 3.61, p=0.597$ ) was significantly attenuated by preischemia administration of various inhibitors/antibodies $4 \mu \mathrm{M}$ Shikonin (PKM2 inhibitor), $10 \mu \mathrm{M}$ JIB-04 (RBP2 inhibitor) and $100 \mathrm{mg} / 4 \mathrm{ml}$ Avastin (VEGF antibody), but this did not occur with vehicle.

In addition, when the retinal protein concentrations of VEGF, HIF-1 $\alpha$, PKM2 and RBP2 were compared, no significant difference existed between the sham eye and the normal eye $(n=4$; VEGF $=0.94 \pm 0.01, p=0.46$; HIF- $1 \alpha=0.92 \pm 0.02, p=0.26$; PKM2 $=0.46 \pm 0.01$, $p=0.10 ; \mathrm{RBP} 2=1.22 \pm 0.09, p=0.37)$.

\section{Discussion}

Ischemia is widely accepted to be involved in visionthreatening retinal disorders such as, proliferative diabetic retinopathy (PDR) [26], wet age-related macular degeneration (wAMD) [27] and central/branch retinal vein or artery occlusion [4]. Furthermore, although, antiVEGF antibodies are clinically utilized world-wide, these are not completely effective when treating these conditions [28]. Moreover, disappointing visual results often occur in patients who have been treated with anti-VEGF drugs, even though the vitreous/subretinal blood and cystoid macular edema have been effectively treated. KDM5A (JARID1A; RBP2) was originally identified as a factor that interacts with the RB gene product $[29,30]$. In mammals, there are four PK isoforms including PKM2, which has been found in the retina, an extension 

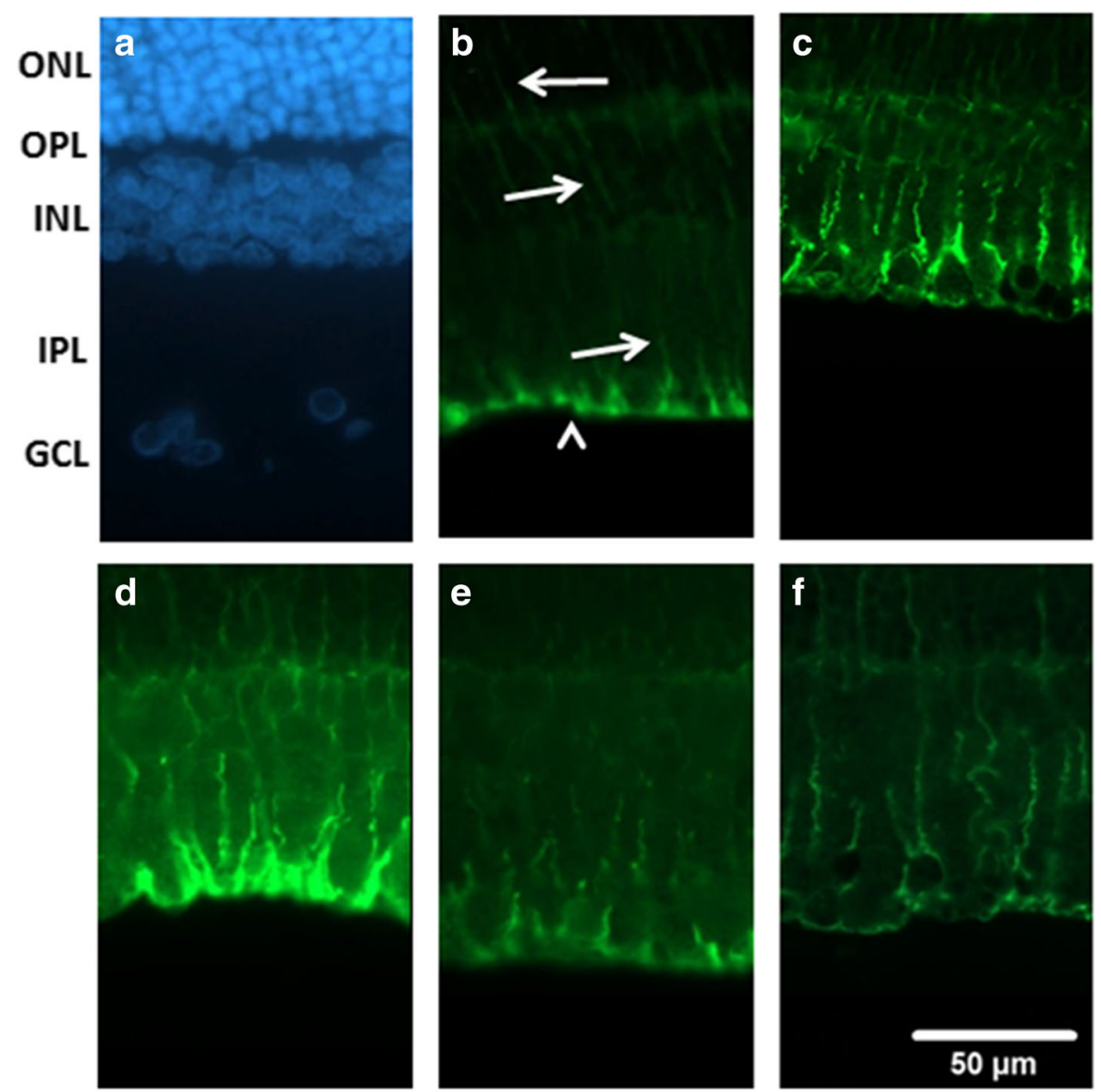

Fig. 6 Vimentin (green) immunohistochemistry. a shows the cellular nucleus of the sham retina labeled with 4,6-diamidine-2-phenylindole dihydrochloride (DAPI, blue). b shows a sham retina with the vimentin immunoreactivity at the end feet (arrow heads) in the GCL and at the processes in the IPL, INL and ONL (arrows). c shows a retina that received I/R and preischemia adminstration of vehicle; in contrast to the sham retina, the anti-vimentin immuolabeling has increased. (d, e, $\mathbf{f}$ ) are sections from retinas that received $\mathrm{I} / \mathrm{R}$ and preischemia administration of $1.35 \mathrm{~g} / \mathrm{kg} /$ day XFZYD (d, XFZYD 1.35 + I/R), $2.7 \mathrm{~g} / \mathrm{kg} /$ day XFZYD (e, XFZYD $2.7+\mathrm{I} / \mathrm{R}$ ) or postischemia administration of $2.7 \mathrm{~g} / \mathrm{kg} /$ day XFZYD $\left(\mathbf{f}, I / R+X F Z Y D_{2.7}\right)$. Moreover, this ischemia-induced alteration is clearly and dose-dependently reduced when the ischemic retina is preadministrated with 1.35 and $2.7 \mathrm{~g} / \mathrm{Kg} /$ day XFZYD. Postischemia administration of $2.7 \mathrm{~g} / \mathrm{Kg} /$ day XFZYD also clearly attenuated this ischemia-induced alteration. ONL: outer nuclear layer, OPL: outer plexiform layer, INL: inner nuclear layer, IPL: inner plexiform layer, GCL: ganglion cell layer. Scale bar $=50 \mu \mathrm{m}$

of the central nervous system, and the brain [31-33]. Avastin is widely known to target all VEGF-A isoforms; isotype 165 is most abundant and biologically active in the eye. The mode of action of another recently launched anti-VEGF aflibercept is involved in VEGF-A, VEGF-B and placental growth factor. As mentioned in the Introduction, PKM2 and RBP2 co-activate HIF- $1 \alpha$, which further triggers VEGF secretion and induces possible subsequent angiogenesis in the ischemic/hypoxic conditions $[6,7,34-36]$. However, there remained a need to investigate whether PKM2 might be an upstream factor that links with the activation of RBP2.

Furthermore, there is also a clinical necessity to identify anti-ischemic agents that possess novel pharmaceutical mechanisms, such as blocking RBP2 and PKM2. The enhanced mRNA/protein concentrations of RBP2 and PKM2, as well as the consequential stimulation of HIF- $1 \alpha$ and VEGF mRNA/protein levels as measured during the present investigation are clearly associated with retinal ischemia and, possibly, wAMD. As also mentioned in the Introduction, XFZYD has been found to potentiate recombinant tPA-mediated neuroprotection against ischemic stroke in the rats [11] and act as an antioxidant. It is also well known that Radix paeoniae rubra, Rhizoma chuanxiong, Semen pruni persicae, and Carthamus tinctorius have an ability to ameliorate the blood circulation and clean up the blood clot as mentioned [11, 13, 14, 16-18, 37]. If the present study helps to identify novel protective mechanisms, CJDHW could offer novel means of coping with the various retinal ischemic diseases mentioned earlier that threaten vision. 

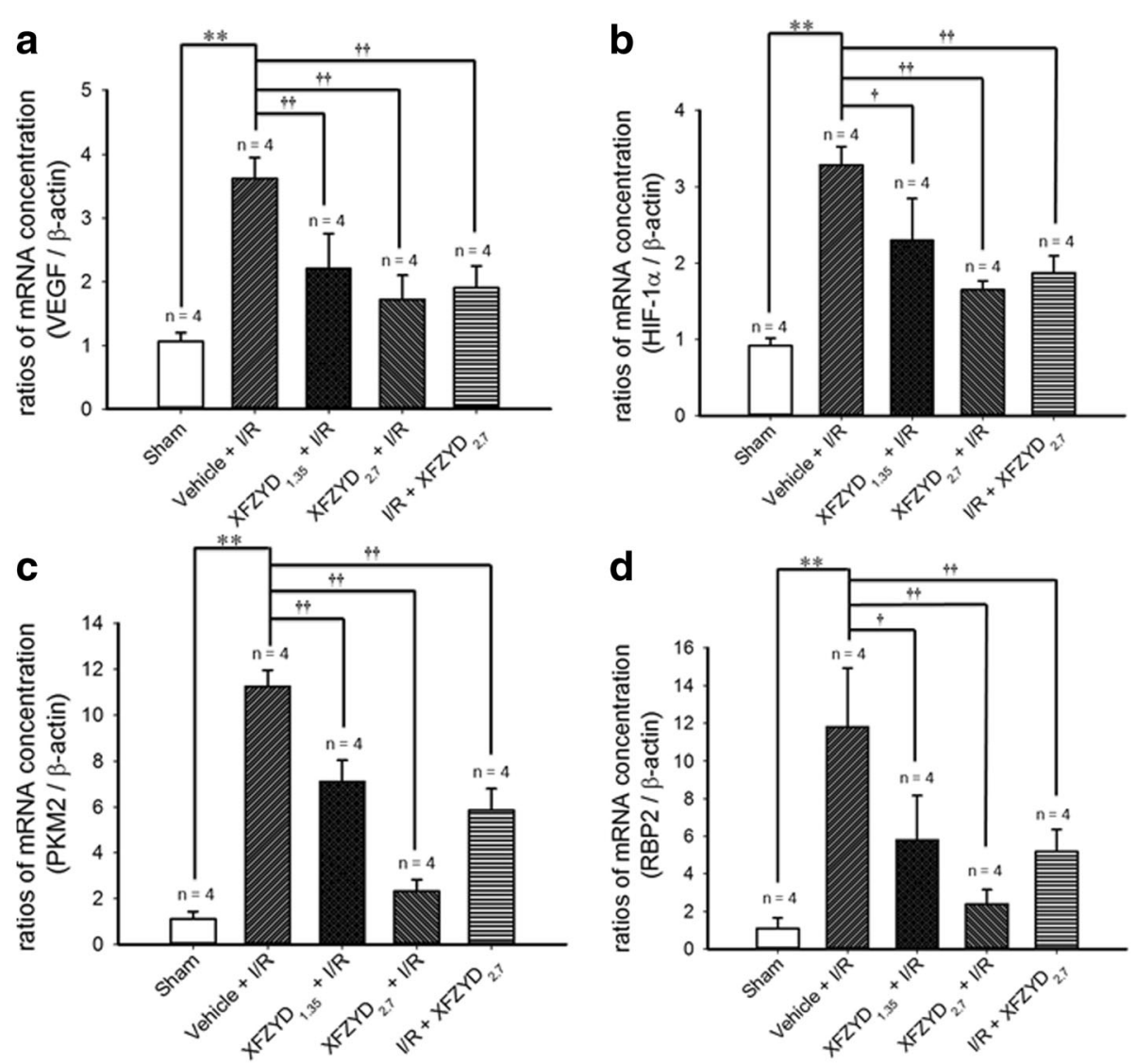

Fig. 7 The ratios of the mRNA concentrations of VEGF, HIF-1a, PKM2 and RBP2 relative to that of $\beta$-actin. Total mRNA was extracted from the sham retinas or the ischemic retinas pretreated with vehicle, a low dose XFZYD $(1.35 \mathrm{~g} / \mathrm{Kg} /$ day), a high dose XFZYD (2.7 g/kg/day), or posttreated with a high dose XFZUD. The mRNA concentration ratios of VEGF (a), HIF-1a (b), PKM2 (c) and RBP2 (d) relative to $\beta$-actin were calculated. The mean values \pm SD $(n=4)$ was shown for each bar. ${ }^{* *}(p<0.01)$ represents significance (Sham vs. Vehicle $\left.+\mathrm{l} / \mathrm{R}\right)$. $+(p<0.05)$ or $+\dagger(p<0.01)$ represents significance (Vehicle + I/R vs. XFZYD $1.35+$ I/R, XFZYD $2.7+$ I/R, or I/R + XFZYD 2.7$)$. VEGF: vascular endothelial growth factor, HIF-1a: hypoxia inducible factor 1a, PKM2: pyruvate kinase M2, RBP2: retinoblastoma-binding protein 2

GFAP and Vimentin immunoreactivity were enhanced in Müller cells following retinal I/R [3], and this is supported by the current result (Figs. 5c and 6c). Dysfunctional Müller cells produce a negative influence on normal ERG b-wave [3, 38, 39], which is also found in this present results (Fig. 1). When retinas are subjected to ischemia and preadministrated with vehicle, enhanced vimentin/GFAP immunoreactivity was found to be present simultaneously with the reduction in b-wave amplitude. Notably, these ischemic changes were mitigated when there was preischemia or postischemia administration of XFZUD to the experimental rats.

After retinal I/R, glutamate receptor-containing neurons, for example RGCs and amacrines, which are present in the inner retina are widely accepted to be liable to injury $[1,3,24,25,39]$. In the present study, following I/R, it was confirmed that the number of RGCs was significantly decreased (Fig. $2 b$ and f) and retinal thickness, especially inner retinal thickness, was significantly reduced
(Fig. $3 \mathrm{~b}$ and $\mathrm{f}$ ). In addition, the result of ChAT immunohistochemistry showed that the number of the amacrine cell bodies was significantly fewer (Fig. 4c and g). Of particular clinical importance, our findings also reveal that preischemia or postischemia administration of XFZYD is able to bring about a significant counteraction of these ischemic features, namely an attenuation of the ischemia-induced decrease in the number of the RGCs (Fig. 2c f), an alleviation of the ischemia-associated decrease in the inner/whole retina thickness (Fig. 3c f), as well as mitigation of the ischemia-related reduction in amacrine cell bodies (Fig. 4d g).

Previous studies have found that HIF- $1 \alpha$ plays a vital part in the activation of hypoxia related VEGF release $[6,35,40]$. Moreover, Luo et al. [40] found that PKM2 reacts with HIF- $1 \alpha$ in a physical and functional manner to trigger the linkage of HIF-1 $\alpha$ with target genes, including coactivators and gene transcription. Moreover, Qi et al. [35] indicated that the RBP2 protein is able to trigger 


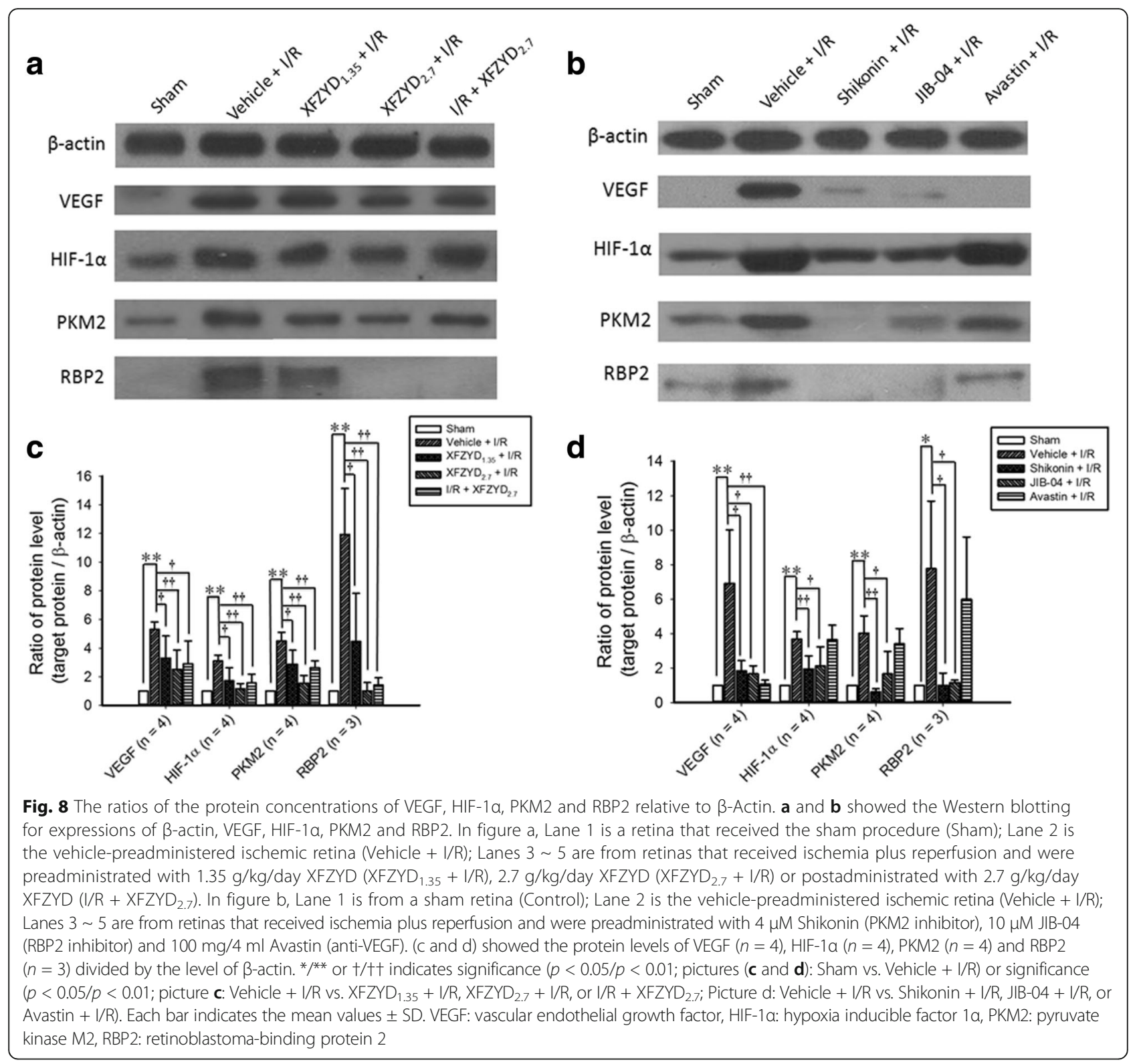

HIF-1 $\alpha$ upregulation and, which in turn stimulates VEGF release. In the present study, it has been verified that the mRNA/protein levels of VEGF, HIF- $1 \alpha$, PKM2 and RBP2 (Figs 7 and 8) are increased in the ischemic retina. As shown by Fig. 8, the effect of JIB-04 on the mean protein levels of RBP2 relative to effect of XFZUD on the mean protein levels of RBP2 was 1.16 to $1.00(p=0.668)$. As discussed in the beginning, PKM2 and RBP2 co-activate HIF- $1 \alpha$ and then stimulates VEGF release $[35,36]$. Not inconsistently with the present result, preischemia or postischemia administration of XFZYD significantly counteracted these ischemiainduced increases (Fig. 8). Taken together, this implies that XFZYD might be able to prevent or protect the defined retinal ischemic changes via a synergistic inhibition of RBP2 and PKM2 as well as by the further down-regulation of HIF- $1 \alpha$ and a subsequent reduction in VEGF-A secretion.

The Rhesus monkey studies [41, 42] have indicated that CRAO of up to 240 min leads to disastrous permanent retinal injury. BRAO eyes that have poorer presenting corrected vision are unlikely to spontaneously improve in the vision and this could result in persistent retinal injury [43, 44]. Topical brimonidine and somatostatin had been shown to act as neuroprotectants and seem to attenuate morbidity due to background diabetic retinopathy (BDR) as well as any deterioration of BDR into PDR [45]. As mentioned earlier, hypoxia, mediated by HIF- $1 \alpha$, both aggravates cellular injury and inflammation as well as plays an 
important role in angiogenesis [46]. The increased levels of HIF- $1 \alpha$ further stimulates the overexpression of VEGF and VEGFR [47], which in turn promotes endothelium growth and new vessel formation, namely angiogenesis [11]. A recent report has indicated that XFZYD significantly reduces the level of HIF- $1 \alpha$ and, as a consequence, VEGF [12]. In addition to the decoction's antiangiogenic and protective effects, XFZYD would appear to have a potentially important role in preventive medicine, while at the same time providing a relevant and important pharmaceutical effect when one has a familial morbidity or have suffered from previous vision-threatening retinal ischemic disorders such as, wAMD, DR, glaucoma, CRAO, BRAO, CRVO or BRVO.

\section{Conclusion}

The present study has clearly demonstrated various retinal ischemic changes, namely a significant decrease in the amplitudes of ERG b-wave (indexing Müller and bipolar cells), a significant less numerous RGCs, a significantly reduced inner/whole retinal thickness, and a significant loss of the ChAT immunolabeling amacrine cells as well as an obvious enhancement in GFAP/Vimentin immunolabeling (indexing Müller cells). In addition, significant upregulation of the mRNA/protein levels of VEGF, HIF-1 $\alpha$, PKM2 and RBP2 were also found in the ischemic retina. Importantly, the harmful influences of these aspects of ischemia were alleviated in a dose responsive and significant manner when XFZYD was applied for seven consecutive days before or after retinal ischemia. In particular, the increases in the ischemia-associated VEGF, HIF-1 $\alpha$, PKM2 and RBP2 increases were blunted by XFZYD. When our findings are taken as a whole, XFZYD would seem to have a preventive or protective effect on retinal ischemia via the downregulation of HIF- $1 \alpha$ expression and a reduction in VEGF secretion; this ocurrs via an inhibition of RBP2 and PKM2.

\section{Additional file}

Additional file 1: XFZUD No. of rats. (PDF $158 \mathrm{~kb}$ )

\section{Abbreviations}

AMD: age-related macular degeneration; ANOVA: analysis of variance: ARRIVE: Animal Research: Reporting of In Vivo Experiments; BCVA: best corrected visual acuity.; BRAO: branch retinal artery occlusion; BRVO: branch retinal vein occlusion; CDNA: complementary DNA; ChAT: choline acetyltransferase; CHGH: Cheng Hsin General Hospital; CHIACUC: Institutional Animal Care and Use Committee at $\mathrm{CHGH}$; CRAO: central retinal artery occlusion; CRVO: central retinal vein occlusion; Ct: cycle threshold; DAPI: 4,6-diamidine-2-phenylindole dihydrochloride; ERG: electroretinogram,; FITC: fluorescein isothiocyanate; GCL: ganglion cell layer; GFAP: glial fibrillary acidic protein; HIF-1a: hypoxia-inducible factor-1a; HIOP: high intraocular pressure; HSYA: hydroxysafflor yellow A; I/R: ischemia/reperfusion; INL: inner nuclear layer; IPL: inner plexiform layer; PBS: phosphate-buffered saline; PCR: polymerase chain reaction; PDR: proliferative diabetic retinopathy;
PKM2: pyruvate kinase M2; PVDF: polyvinylidene difluoride; RBP2: retinoblastoma-binding protein 2; RGCs: retinal ganglion cells; RPE: retinal pigment epithelium; SD: standard deviation; tPA: tissue plasminogen activator; VEGF: vascular endothelium growth factor; WAMD: wet age-related macular degeneration; XFZYD: Xue-Fu-Zhu-Yu decoction

\section{Acknowledgements}

Sincere thanks are expressed for the research grant $\mathrm{CH} 104-22$. Heartfelt gratitude is owed to Ms. Huei-Wen Shiu for her experienced skills in biomolecular methods and to Professor Ralph Kirby for his expertise in revising the final draft of the manuscript.

\section{Funding}

"Not applicable".

Availability of data and materials

All data generated or analysed during this study are included in this published article [and its supplementary information files].

Authors' contributions

HMC and LH were the designers of this project. SQT and XG carried out the experimental procedures as well as writing the first draft of the manuscript. $J H L, H T P, L X W$, and LH together with HMC were involved in the analysis of the results and the revision of the manuscript. All authors read, approved and have unanimously endorsed the final manuscript.

\section{Ethics approval and consent to participate}

Methods.

Animals (1st sentence).

All animals were treated according to the Association for Research in Vision and Ophthalmology Statement for the Use of Animals in Ophthalmology and Vision Research, and all the animal experiments were agreed by the Institutional Animal Care and Use Committee at Cheng Hsin General Hospital (CHGH; Taipei, Taiwan; Approval No: CHIACUC 104-05).

Consent for publication

"Not applicable".

\section{Competing interests}

No competing financial interests exist.

\section{Publisher's Note}

Springer Nature remains neutral with regard to jurisdictional claims in published maps and institutional affiliations.

\section{Author details}

${ }^{1}$ Department of Ophthalmology, Affiliated Hospital of Taishan Medical University, Taishan, Shandong, China. ${ }^{2}$ Department of Pharmacology, School of Medicine, Shandong University, Jinan, Shandong, China. ${ }^{3}$ Department of Ophthalmology, Cheng Hsin General Hospital, Taipei, Taiwan. ${ }^{4}$ Institute of Pharmacology, School of Medicine, National Yang-Ming University, Taipei, Taiwan. ${ }^{5}$ Division of Basic Chinese Medicine, National Research Institute of Chinese Medicine, Ministry of Health and Welfare, Taipei, Taiwan.

${ }^{6}$ Department of Chinese Medicine, School of Chinese Medicine, China Medical University, Taichung, Taiwan.

Received: 29 January 2017 Accepted: 23 June 2017

Published online: 14 July 2017

References

1. Osborne NN, Casson RJ, Wood JP, Chidlow G, Graham M, Melena J. Retinal ischemia: mechanisms of damage and potential therapeutic strategies. Prog Retin Eye Res. 2004;23(1):91-147. doi:10.1016/j. preteyeres.2003.12.001.

2. Peng PH, Chao HM, Juan SH, Chen CF, Liu JH, Ko ML. Pharmacological preconditioning by low dose cobalt protoporphyrin induces heme oxygenase-1 overexpression and alleviates retinal ischemia-reperfusion injury in rats. Curr Eye Res. 2011;36(3):238-46. doi:10.3109/02713683.2010. 539760 . 
3. Chao HM, Chen IL, Liu JH. S-allyl L-cysteine protects the retina against kainate excitotoxicity in the rat. Am J Chin Med. 2014;42(3):693-708. doi:10.1142/S0192415X14500451.

4. Wurm A, landiev I, Uhlmann S, Wiedemann P, Reichenbach A, Bringmann A, et al. Effects of ischemia-reperfusion on physiological properties of Müller glial cells in the porcine retina. Invest Ophthalmol Vis Sci. 2011;52(6):3360-7. doi:10.1167/iovs.10-6901.

5. Zarbin MA. Current concepts in the pathogenesis of age-related macular degeneration. Arch Ophthalmol. 2004;122(4):598-614.

6. Håkansson G, Gesslein B, Gustafsson L, Englund-Johansson U, Malmsjö M. Hypoxia-inducible factor and vascular endothelial growth factor in the neuroretina and retinal blood vessels after retinal ischemia. J Ocul Biol Dis Infor. 2010;3(1):20-9. doi:10.1007/s12177-010-9050-6.

7. Liu JH, Wann H, Chen MM, Pan WH, Chen YC, Liu CM, et al. Baicalein significantly protects human retinal pigment epithelium cells against $\mathrm{H}_{2} \mathrm{O}_{2}$ -induced oxidative stress by scavenging reactive oxygen species and downregulating the expression of matrix metalloproteinase-9 and vascular endothelial growth factor. J Ocul Pharmacol Ther. 2010;26(5):421-9. doi:10.1089/jop.2010.0063.

8. Wang L, Chang J, Varghese D, Dellinger M, Kumar S, Best AM, et al. A small molecule modulates Jumonji histone demethylase activity and selectively inhibits cancer growth. Nat Commun. 2013;4:2035. doi:10.1038/ ncomms3035.

9. Li W, Liu J, Zhao Y. PKM2 inhibitor shikonin suppresses TPA-induced mitochondrial malfunction and proliferation of skin epidermal JB6 cells. Mol Carcinog. 2014 May;53(5):403-12. doi:10.1002/mc.21988.

10. Fu C, Xia Z, Liu Y, Lu H, Zhang Z, Wang Y, et al. Qualitative analysis of major constituents from Xue fu Zhu Yu decoction using ultra high performance liquid chromatography with hybrid ion trap time-of-flight mass spectrometry. J Sep Sci. 2016:39(17):3457-68. doi:10.1002/jssc.201600083.

11. Lee JJ, Hsu WH, Yen TL, Chang NC, Luo YJ, Hsiao G, et al. Traditional Chinese medicine, Xue-fu-Zhu-Yu decoction, potentiates tissue plasminogen activator against thromboembolic stroke in rats. J Ethnopharmacol. 2011;134(3):824-30. doi:10.1016/j.jep.2011.01.033.

12. Zhou YN, Sun MY, Mu YP, Yang T, Ning BB, Ren S, et al. Xuefuzhuyu decoction inhibition of angiogenesis attenuates liver fibrosis induced by $\mathrm{CCl}_{4}$ in mice. J Ethnopharmacol. 2014;153(3):659-66. doi:10.1016/j.jep.2014.03.019.

13. Chao HM, Chen YH, Liu JH, Lee SM, Lee FL, Chang Y, et al. Iron-generated hydroxyl radicals kill retinal cells in vivo: effect of ferulic acid. Hum Exp Toxicol. 2008a;27(4):327-39. doi:10.1177/0960327108092294.

14. Chao HM, Lin DE, Chang Y, Hsu WM, Lee SM, Lee FL, et al. Ferulic acid, but not tetramethylpyrazine, significantly attenuates retinal ischemia/ reperfusion-induced alterations by acting as a hydroxyl radical scavenger. J Ocul Pharmacol Ther. 2008b;24(5):461-72. doi:10.1177/0960327108092294.

15. Zhu H, Wang Y, Liu Z, Wang J, Wan D, Feng S, et al. Antidiabetic and antioxidant effects of catalpol extracted from Rehmannia glutinosa (Di Huang) on rat diabetes induced by streptozotocin and high-fat, high-sugar feed. Chin Med. 2016;11:25-34. doi:10.1186/s13020-016-0096-7.

16. Zhang $Y$, Li H, Huang M, Huang M, Chu K, Xu W, et al. Paeoniflorin, a monoterpene glycoside, protects the brain from cerebral ischemic injury via inhibition of apoptosis. Am J Chin Med. 2015;43(3):543-57. doi:10.1142/ S0192415X15500342.

17. Liu L, Duan JA, Tang Y, Guo J, Yang N, Ma H, et al. Taoren-Honghua herb pair and its main components promoting blood circulation through influencing on hemorheology, plasma coagulation and platelet aggregation. J Ethnopharmacol. 2012;139(2):381-7. doi:10.1016/j.jep.2011.11.016.

18. Wang X, Ma Z, Fu Z, Gao S, Yang L, Jin Y, et al. Hydroxysafflor yellow a protects neurons from excitotoxic death through inhibition of NMDARs. ASN Neuro. 2016:8(2):1-19. doi:10.1177/1759091416642345.

19. Xiong $X, G u$ L, Wang Y, Luo Y, Zhang H, Lee J, et al. Glycyrrhizin protects against focal cerebral ischemia via inhibition of T cell activity and HMGB1mediated mechanisms. J Neuroinflammation. 2016;13(1):241-52. doi:10. 1186/s12974-016-0705-5.

20. Cheong CU, Yeh CS, Hsieh YW, Lee YR, Lin MY, Chen CY, et al. Protective effects of Costunolide against hydrogen peroxide-induced injury in PC12 cells. Molecules. 2016 Jul 9;21(7):898-907. doi:10.3390/ molecules21070898.

21. Park WH, Kang S, Piao Y, Pak CJ, Oh MS, Kim J, et al. Ethanol extract of Bupleurum Falcatum and saikosaponins inhibit neuroinflammation via inhibition of NF-kB. J Ethnopharmacol. 2015 Nov 4;174:37-44. doi:10.1016/j. jep.2015.07.039.
22. Xue S, Chen X, Lu J, Jin L. Protective effect of sulfated Achyranthes bidentate polysaccharides on streptozotocin-induced oxidative stress in rats. Carbohydr Polym. 2009;75(3):415-9. doi:10.1016/j.carbpol.2008.08.003.

23. Lim JH, Kim TW, Park SJ, Song IB, Kim MS, Kwon HJ, et al. Protective effects of Platycodon grandiflorum aqueous extract on thioacetamide-induced fulminant hepatic failure in mice. J Toxicol Pathol. 2011;24(4):223-8. doi:10.1293/tox.24.223.

24. Chen YQ, Pan WH, Liu JH, Chen MM, Liu CM, Yeh MY, et al. The effects and underlying mechanisms of S-allyl I-cysteine treatment of the retina after ischemia/reperfusion. J Ocul Pharmacol Ther. 2012;28(2):110-7. doi:10.1089/ jop.2011.0099.

25. Chao HM, Chuang MJ, Liu JH, Liu XQ, Ho LK, Pan WH, et al. Baicalein protects against retinal ischemia by antioxidation, antiapoptosis, downregulation of HIF-1a, VEGF, and MMP-9 and upregulation of HO-1. J Ocul Pharmacol Ther. 2013;29(6):539-49. doi:10.1089/jop.2012.0179.

26. Thomas RL, Dunstan FD, Luzio SD, Chowdhury SR, North RV, Hale SL, et al Prevalence of diabetic retinopathy within a national diabetic retinopathy screening service. $\mathrm{Br} J$ Ophthalmol. 2015;99(1):64-8. doi:10.1136/bjophthalmol-2013-304017.

27. Park SJ, Kwon KE, Choi NK, Park KH, Woo SJ. Prevalence and incidence of exudative age-related macular degeneration in south Korea: a nationwide population-based study. Ophthalmology. 2015;122(10):2063-70. doi:10.1016/ j.ophtha.2015.06.018.

28. Opremcak E, Rehmar AJ, Ridenour CD, Borkowski LM, Kelley JK. Restoration of retinal blood flow via translumenal Nd:YAG embolysis/embolectomy (TYL/E) for central and branch retinal artery occlusion. Retina. 2008;28:22635. doi:10.1097/IAE.0b013e31814b1d6e.

29. Nishibuchi G, Shibata Y, Hayakawa T, Hayakawa N, Ohtani Y, Sinmyozu K, et al. Physical and functional interactions between the histone H3K4 demethylase KDM5A and the nucleosome remodeling and deacetylase (NuRD) complex. J Biol Chem. 2014 Oct 17;289(42):28956-70. doi:10.1074/ jbc.M114.573725.

30. Horton JR, Engstrom A, Zoeller EL, Liu X, Shanks JR, Zhang X, et al. Characterization of a linked Jumonji domain of the KDM5/JARID1 family of histone H3 lysine 4 demethylases. J Biol Chem. 2016 Feb 5;291(6):2631-46. doi:10.1074/jbc.M115.698449.

31. Miwa S, Fujii H. Pyruvate kinase deficiency. Clin Biochem. 1990;23(2):155-7. PMID: 2197027

32. Imamura, K., Tanaka, T. Pyruvate kinase isozymes from rat. In: Willis, AW, editor. Methods in Enzymology. Academic Press; 1982. p. 150-165.

33. Lunt SY, Muralidhar V, Hosios AM, Israelsen WJ, Gui DY, Newhouse L, et al. Pyruvate kinase isoform expression alters nucleotide synthesis to impact cell proliferation. Mol Cell. 2015;57(1):95-107. doi:10.1016/j.molcel.2014.10.027.

34. Azoitei N, Becher A, Steinestel K, Rouhi A, Diepold K, Genze F, et al. PKM2 promotes tumor angiogenesis by regulating HIF-1a through NF-KB activation. Mol Cancer. 2016;15:3-17. doi:10.1186/s12943-015-0490-2.

35. Qi L. Zhu, Li SH, Si LB, Hu LK, Tian H. Retinoblastoma binding protein 2 (RBP2) promotes HIF-1a-VEGF-induced angiogenesis of non-small cell lung cancer via the Akt pathway. PLoS One. 2014;9(8):e106032-43. doi:10.1371/ journal.pone.0106032.

36. Ng SK, Wood JP, Chidlow G, Han G, Kittipassorn T, Peet DJ, et al. Cancer-like metabolism of the mammalian retina. Clin Exp Ophthalmol. 2015;43(4): 367-76. doi:10.1111/ceo.12462.

37. Kim SH, Park HS, Hong MJ, Yoo JY, Lee H, Lee JA, et al. Tongqiaohuoxue decoction ameliorates obesity-induced inflammation and the prothrombotic state by regulating adiponectin and plasminogen activator inhibitor-1. J Ethnopharmacol. 2016 Nov 4;192:201-9. doi:10.1016/j.jep.2016. 07.023 .

38. Brown KT. The electroretinogram: its components and their origins. Vis Res. 1968:8(6):633-77. PMID: 4978009

39. Stockton RA, Slaughter MM. B-wave of the electroretinogram. A reflection of ON bipolar cell activity. J Gen Physiol. 1989;93(1):101-22. PMCID: PMC2216200

40. Luo W, Hu H, Chang R, Zhong J, Knabel M, O'Meally R, et al. Pyruvate kinase M2 is a PHD3-stimulated coactivator for hypoxia-inducible factor 1. Cell. 2011;145(5):732-44. doi:10.1016/j.cell.2011.03.054

41. Hayreh SS, Jonas JB. Optic disk and retinal nerve fiber layer damage after transient central retinal artery occlusion: an experimental study in rhesus monkeys. Am J Ophthalmol. 2000:129:786-95. PMID: 10926989

42. Hayreh SS, Zimmerman MB, Kimura A, Sanon A. Central retinal artery occlusion. Retinal survival time. Exp. Eye Res. 2004;78:723-36. PMID: 15106952 
43. Mason JO III, Shah AA, Vail RS, Nixon PA, Ready EL, Kimble JA. Branch retinal artery occlusion: visual prognosis. Am J Ophthalmol. 2008;146:455-7. doi:10.1016/j.ajo.2008.05.009.

44. Hsu TK, Chen SJ, Lei J, Wu Z, Lin CC, Chen MM, et al. Embolus-induced branch retinal artery occlusion with a presenting best-corrected visual acuity of $<6 / 12$ and visual field defect: yag embolectomy safely restores arteriolar perfusion and/or visual function. Retin Cases Brief Rep. 2013;7(3): 210-6. doi:10.1097//CB.0b013e3182852370.

45. Hernandez C, Simo R. Somatostatin replacement: a new strategy for treating diabetic retinopathy. Curr Med Chem. 2013;20(26):3251-7. PMID: 23745546

46. Rosmorduc O, Housset C. Hypoxia: a link between fibrogenesis, angiogenesis, and carcinogenesis in liver disease. Semin Liver Dis. 2010;30:258-70. doi:10.1055/s-0030-1255355.

47. Nath B, Szabo G. Hypoxia and hypoxia inducible factors: diverse roles in liver diseases. Hepatology. 2012;55:622-33. doi:10.1002/hep.25497.

Submit your next manuscript to BioMed Central and we will help you at every step:

- We accept pre-submission inquiries

- Our selector tool helps you to find the most relevant journal

- We provide round the clock customer support

- Convenient online submission

- Thorough peer review

- Inclusion in PubMed and all major indexing services

- Maximum visibility for your research

Submit your manuscript at www.biomedcentral.com/submit
Biomed Central 